\title{
Finite Element Modeling and Nonlinear Analysis for Seismic Assessment of Off-Diagonal Steel Braced RC Frame
}

\author{
Keyvan Ramin ${ }^{1), *}$, and Mitra Fereidoonfar ${ }^{2)}$
}

(Received November 9, 2013, Accepted August 19, 2014, Published online September 16, 2014)

\begin{abstract}
The geometric nonlinearity of off-diagonal bracing system (ODBS) could be a complementary system to covering and extending the nonlinearity of reinforced concrete material. Finite element modeling is performed for flexural frame, $x$-braced frame and the ODBS braced frame system at the initial phase. Then the different models are investigated along various analyses. According to the experimental results of flexural and x-braced frame, the verification is done. Analytical assessments are performed in according to three dimensional finite element modeling. Nonlinear static analysis is considered to obtain performance level and seismic behaviour, and then the response modification factors calculated from each model's pushover curve. In the next phase, the evaluation of cracks observed in the finite element models, especially for RC members of all three systems is performed. The finite element assessment is performed on engendered cracks in ODBS braced frame for various time steps. The nonlinear dynamic time history analysis accomplished in different stories models for three records of Elcentro, Naghan and Tabas earthquake accelerograms. Dynamic analysis is performed after scaling accelerogram on each type of flexural frame, x-braced frame and ODBS braced frame one by one. The base-point on RC frame is considered to investigate proportional displacement under each record. Hysteresis curves are assessed along continuing this study. The equivalent viscous damping for ODBS system is estimated in according to references. Results in each section show the ODBS system has an acceptable seismic behaviour and their conclusions have been converged when the ODBS system is utilized in reinforced concrete frame.
\end{abstract}

Keywords: FEM, seismic behaviour, pushover analysis, geometric nonlinearity, time history analysis, equivalent viscous damping, passive control, crack investigation, hysteresis curve.

\section{Introduction}

Since, the experimental researches are very expensive and time-consuming (Altun and Birdal 2012), the application of computer modeling methods as initial investigation and also in the next step, calibration of present computer models with a similar previous experimental research can be a certainty. In this study, the finite element model is calibrated in the first step for flexural frame and x-braced frame. Then the main model is simulated according to verified characteristics of the last step's model. The FE model is considered to different analysis and design.

The design of seismic resistant structures in seismic regions should satisfy two criteria. First, under frequent and low to moderate earthquakes, the structure should have

\footnotetext{
${ }^{1)}$ Structural \& Mechanical Department, Advance Researches \& Innovations, Aisan Disman Consulting Engineers Inc., 6718783559 Kermanshah, Iran.

*Corresponding Author; E-mail: keyvan_ramin@yahoo.com

${ }^{2)}$ Department of Structural Engineering, Asians Disman Consulting Engineers, Kermanshah, Iran.
}

Copyright ( $\odot$ The Author(s) 2014. This article is published with open access at Springerlink.com sufficient strength and stiffness to control deflection and prevent any structural damage. Second, under rare and severe earthquakes the structures must have sufficient ductility to prevent collapse (Roeder and Popov 1977).

Reinforced concrete structures usually have dual behaviour against lateral loads, first the behaviour before cracking (pre-cracking) by limited resistant and the other behaviour after cracking (post-cracking) by increasing the ductility. Although the reinforced concrete behaviour of post cracking stages is complicated and extended by multi steps (elastic, yielding, elastic-perfectly-plastic (EPP), plastic and collapse), merely whatever is obvious in all steps after cracking is the high amount of ductility proportional to the other stage.

So, many kinds of lateral load bearings have been used in steel and Reinforced Concrete (RC) structures for recent years, which contain useful performances.

The important thing that should be mentioned here is if the additional system to $\mathrm{RC}$ frame being the occasion of imperfect energy absorption in reinforced concrete members, then some part of the structure will not contribute in energy dissipation and actually this system's application has no economic advantages. For example in a reinforced concrete x-braced frame, just upon the imposing lateral loads, the diagonal members of bracing system make a directional component with lateral loads and so they experience a high 
percent of those lateral load. Now if the lateral loads be increased, the axial plastic hinge will be formed in steel bracing members before the formation of flexural plastic hinge in $\mathrm{RC}$ members. By continuing the imposed lateral load on the $\mathrm{x}$-braced $\mathrm{RC}$ frame, the limited nonlinear behaviour is started in term of large deformation in braced frame members. Based on the high capacity of energy absorption in diagonal steel bracing members proportional to reinforced concrete members, the $\mathrm{RC}$ frame will be collapsing in possible minimum time after occurrence the large displacement and collapse in diagonal steel members and it won't let reinforced concrete members to make plastic hinge in a short time domain. So this phenomenon will not let the reinforced concrete members being contributed in energy dissipation and on the other hand the plastic limit is abbreviated along this short time for the load transferring.

The off-diagonal bracing system induces new properties of the reinforced concrete frame. The different performances of the RC frame braced by off-diagonal bracing system (ODBS) are about the each member's opportunity and possibility for the formation of plastic hinges.

The specific geometry of the ODBS, one of the steel bracing members absorb the amount of energy until, cracking extend to RC members. Additional to large deformation in third member of ODBS, the cracking is increased in RC frame, even may be observed the frame's plastic hinges. While the other steel diagonal members, being oriented in parallel form, it can be a confident fuse to prevent declining the lateral resistance of the RC frame.

The preceding reasons demonstrate the ODBS braced frame has two stages behaviour for the elastic, elasto-plastic and plastic treatments. The extended amount of energy dissipation for ODBS system is not only because of the inherent nonlinear properties of materials but also the particular nonlinear geometry is effective on damping and energy dissipation and anyhow presents a particular system of passive energy dissipative.

The two basic requirements for seismic design are high stiffness at working load level and large ductility at severe over loadings. These requirements are difficult to be satisfied when the above conventional frames are used. On the contrary, Eccentrically Braced Frames offer an economical framing system satisfying both requirements.

In all types of this system, the vertical components of axial forces in the braces are held in equilibrium by shear and bending moments in short beams of lengths, which is the active links. Active links are designed to remain elastic at working loads and deform inelastic on over loading of structure, thereby dissipating large amount of energy. In this system the hazardous brace buckling can be entirely prevented since the link acts as fuse to limit the brace axial force. Also this frame has a much greater lateral resisting capacity than that of an MRF if the beam section used are the same (Mastrandrea and Piluso 2009a, b; Mastrandrea and Piluso 2009a, b). On the other hand in ODBS system the third member of bracing has similar treatment to active link but by another mechanism.

\section{Aims and Objectives for this Research}

The main aim of this research is related to investigation of ODBS system's behaviour. Corresponding to the title, in this assessment focused on seismic behaviour of ODBS braced $\mathrm{RC}$ frame under real registered earthquake records and also the spectral forces parallel to exact modeling by finite element method (FEM). FEM models were developed to simulate various RC frames with and without steel bracing systems of three full size frames for nonlinear response up to collapse, using the ANSYS program (ANSYS 2015). Then models verified for several analysis and investigation. As it is known to us, a considerable impact load induced at difference modes of vibration through earthquake and exerted on bracing components if the direction of forces change and components stretch under the influence of components' buckling caused by pressure (Ravi Kumar et al. 2007). This study expects that the amount of lateral forces being transmitted from earth to upper levels, subsequently the effect of impact will decrease as a result of using ODBS, the high energy absorption capacity, in lower floors of the structure. Time history analysis is done for high rise models by different properties. Also several comparisons assessed for applicable results and Conclusions from the current research efforts and recommendations for future studies are included.

\section{Research Background}

Basis on collapse prevention and life safety performance levels, a structure has to experience the large inelastic deformations in term of large capacity of energy dissipation during any excitation. Actually, the reason of structural stability of a system under any inelastic earthquake load is the condition of hysteretic loops, which means the stability of structural system depends on stability of hysteresis curves in each cycles. Such stable loops of a cyclic load or time history acceleration under an earthquake load can be a provision of sufficient ductility and large amount of energy dissipation for structural system's element (Khatib et al. 1988; Asgarian et al. 2010).

For high and medium rise buildings, structural steel has been used extensively due to its high strength and ductile properties. In general, bracing systems are divided into two general types: concentric and eccentric (Ghobarah and Abou Elfath 2001; Kim and Choi 2005; Moghaddam et al. 2005). Concentric braced systems are more desirable because of a relative high stiffness, along with their easy construction and economy aspects; hence these important criteria make this type more common than eccentrically braced frames (Davaran and Hoveidae 2009).

Eccentric braces need more construction accuracy thereby resulting in a decrease of construction speed and higher cost in spite of better stiffness performance and higher energy dissipation (Özhendekci and Özhendekci 2008; Bosco and Rossi 2009). 
This system allows the architects to have more openings in panel areas (Moghaddam and Estekanchi 1995; Moghaddam and Estekanchi 1999). Moreover, because of the cyclic nature of seismic loads, these brace elements are designed symmetrically and so they should perform in two span to work symmetric.

The idea of steel bracing system application in reinforced concrete structures was first suggested for seismic strengthening of concrete buildings. From the viewpoint of both research and application, this idea has been very prevalent during past two decades because of its simplicity, implementation and its lower relative cost compare with shear wall. For example, Sugano and Fujimura performed a series of experiments on a model of one-story frame which had been strengthened through various methods. They examined $\mathrm{x}$-bracing and k-bracing systems and compared them with samples strengthened by concrete and masonry in-filled walls. They aimed to determine the effect of each system on enhancement of in-plane strength and ductility of the samples (Sugano and Fujimura, 1980). Furthermore, Kavamata and Ohnuma demonstrated the possibility of the effective use of steel bracing systems in concrete buildings (Kawamata and Ohnuma 1981).

A model of two spans, two stories reinforced concrete frame in scale of 1:3 was chosen to represent the seismic weakness and behaviour. The strengthened frame was exposed to lateral and gravity loads and its displacements were allowed to increase by one fiftieth of the frame's Original height (inter-story drift). The strengthened inside frame by a ductile steel brace, demonstrated better behavior considerably than the preliminary reinforced concrete frame (Masri and Goel 1996) or applied from outside the frame (Bush et al. 1991).

In 1999, the direct internal use of steel bracing system in concrete frame was studied in laboratory. Experiments were carried out on five one span, one story frame samples with a scale of $1: 2.5$. Two of them had no bracing system but the other three samples strengthened by $\mathrm{x}$-bracing system with different connector's component including bolt and nut, cover of RC column, and gusset plates placed in concrete. Results showed, depending upon various connectors' component, the bracing system considerably increases the equivalent stiffness of the frame and notably changes its behavior. When the bracing system's connector is implanted inside concrete, the performance of frame gets even better and further energy is absorbed. Generally, experiments demonstrated that the bracing system tolerates a major part of lateral load in reinforced concrete frame (Tasnimi and Masoumi 1999).

Dynamic behavior of the concrete buildings strengthened with concentric bracing systems has investigated by Abou Elfath and Ghobarah. A three story building was dynamically analyzed with various earthquake records and the effect of steel bracing system on building as well as the effect of bracing system distribution throughout frame's height was studied. The position of braces investigated the proportional seismic performance, inter-story drift, and damage index to show the effect of this type of bracing systems (Abou Elfath and Ghobarah 2000).
Maheri et al. (2003) first reviewed previous studies on strengthening by steel bracing systems and then investigated three models including a simple frame, a frame strengthened with x-bracing, and a frame strengthened with knee bracing system under lateral load until failure stage. They found that ductility of RC frame is considerably increases when using knee bracing system (Maheri and Akbari 2003).

In 1994, Moghaddam and Estekanchi modeled and tested Off-Centre bracing systems in steel frames for the first time. Later in 1999, they analyzed the seismic behavior of OffDiagonal bracing system. They confirmed that this system's behavior resembles with seismic isolators and play a considerable role in reduction of seismic forces (Moghaddam and Estekanchi 1999, Moghaddam and Estekanchi 1994). All previous studies confirm the effectiveness of steel braces in rehabilitating and retrofitting of $\mathrm{RC}$ frame.

\section{Finite Element Modeling}

\subsection{Models Characteristics}

The flexural RC frame, the basic frame, was designed in according to ACI 318-02 concrete manual. In finite element models used scale of $2 / 5$ same as the scale factor of experimental models and according to other geometric characteristics. The dimensions of $1.76 \mathrm{~m}$ for length, $1.38 \mathrm{~m}$ for height and $0.16 \times 0.14 \mathrm{~m}$ of rectangular section dimensions is considered through the FE modeling of flexural frame. In both of the beam and column reinforcements, 4M10 are assigned for longitudinal reinforcement (Rebar's diameter of M10 is equal to $11.3 \mathrm{~mm}$ ). In the plastic hinge regions (350 $\mathrm{mm}$ from each end), the transverse reinforcement of beams and columns used from $6 \mathrm{~mm}$ steel wires spaced at $35 \mathrm{~mm}$ and for other places far from plastic regions, the $6 \mathrm{~mm}$ steel wires spaced at $70 \mathrm{~mm}$ are used. The beamcolumn joint was transversely reinforced with two $6 \mathrm{~mm}$ wires corresponding to lateral shear force. Also in the $\mathrm{x}$-braced RC frames, the two steel plates of $150 \times$ $150 \times 8 \mathrm{~mm}$ were placed at each corner of the $R C$ frames by cast in place method (Youssefa et al. 2007). Each plate was anchored to the RC frame using four $5 / 8$-inch headed studs as shown in Fig. 1. Self-consolidated concrete with 28 days compressive strength of $40 \mathrm{MPa}$ is used to concrete compressive stress of models. The yield stress of the steel reinforcement applied as $400 \mathrm{MPa}$. A brace by double-angle cross-section, consisting of two $25 \times 25 \times 3.2 \mathrm{~mm}$ angles, by a cross-sectional area of $300 \mathrm{~mm}^{2}$, is selected for the flexural frame $F_{1}$ and also a $C 30 \times 3.5 \mathrm{~mm}$ channel with a cross-sectional area of around $500 \mathrm{~mm}^{2}$ is selected for the frame $F_{\mathrm{X}}$, as indicated in Fig. 1. The yielding capacity of $300 \mathrm{MPa}$ is considered for the bracing members. The braced frame by off-diagonal bracing system $\left(F_{O D B S}\right)$, the RC cross sections and semi-diagonal steel braces are such as characteristics of $F_{X}$ model ( $x$-braced frame) and their difference is only about third member of steel bracing system.

The beam-column joint of the moment frame was transversely reinforced with two $6 \mathrm{~mm}$ steel wires according to the special seismic provisions of the ACI 

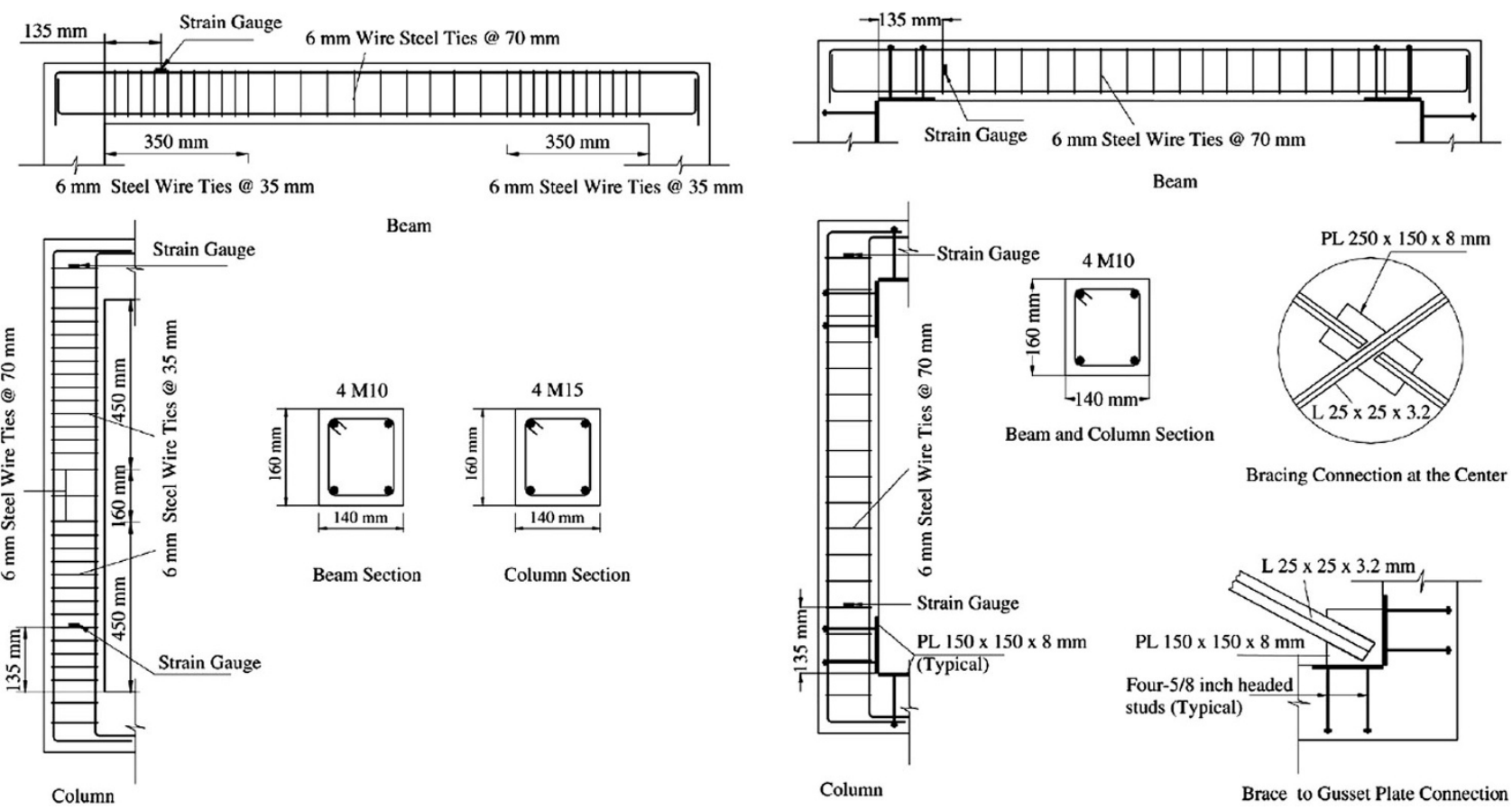

Fig. 1 Experimental characteristics of structural elements (Maheri et al. 2006; Youssefa et al. 2007), for $\mathbf{F}_{\mathbf{1}}$ model, flexural reinforced concrete frame (left) and for $\mathbf{F}_{\mathbf{x}}$ model, $\mathbf{x}$-braced reinforced concrete frame (right) to use for FE models and calibration process.

code (ACI Committee 318 2002). For the braced frame, the column stirrups were continued in the joint by one $6 \mathrm{~mm}$ wire in the joint area. Thus, the additional strength of gusset plates, during the braced frame, the beam-column joints inside the stiffeners are expected to eliminate the undesirable shear failure without the need for any special joint detailing. However, this needs further testing to reach final recommendations (Youssefa et al. 2007). Comparison results of Pushover analysis indicate that OffDiagonal Bracing System can increase lateral flexibility by velocity control or on the other hand by increasing Damping characteristics. In X-Bracing system after yielding steel members, the strength of RC frame was decreased suddenly but in ODBS model, the steel and concrete materials have been contributed better than other models. The schematic finite element model of ODBS and its behaviour are brought in Fig. 2.

\subsection{Material Nonlinearity}

Concrete and steel are the two constituents of RC braced frame. Among them, concrete is much stronger in compression than in tension (tensile strength is of the order of one-tenth of compressive strength). While its tensile stress-strain relationship is almost linear, the stress-strain relationship in compression is nonlinear from the beginning. The Elastic-PerfectlyPlastic (EPP) model for steel, which is used in this work, assumes the stress to vary linearly with strain up to yield point and remain constant beyond that (Anam and Shoma 2011).

In this research the Willam and Warnke (1974), the yield and failure criteria, is considered for concrete model behaviour. Also, since the SAP2000 (2010) assumption applies the Drucker-Prager criteria for concrete material modeling and its behaviour, both of mentioned criteria's are considered in analysis of models. By this method, the analytical comparison of applied criteria's is done.
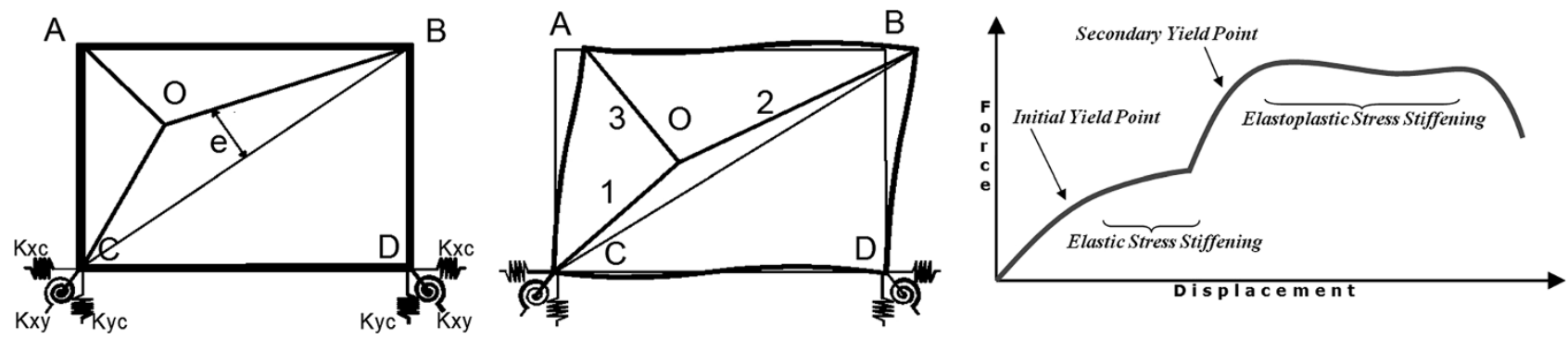

Fig. 2 (Left) Schematic models for off-diagonal bracing system; (Right) Schematic force-displacement diagram by two yield points and ductile behaviour to high energy dissipation. 
In steel material modeling, the bilinear curve of behaviour is used. This model is included in two parts, linear and Elastic-Plastic behaviour. The elasticity modulus is $E_{1}=2 \times 10^{6} \mathrm{~kg} / \mathrm{cm}^{2}$ for linear part and $E_{2}=2 \times 10^{4} \mathrm{~kg} /$ $\mathrm{cm}^{2}$ for the nonlinear part of the behaviour. These specifications are indicated in Fig. 3.

On the other hand, the uniaxial stress-strain relationship for confined concrete, known as the modified Kent and Park model, has been incorporated in the FE model constructed here. This model shows a good agreement with the experimental results (Kent and Park 1971; Scott et al. 1982) and offers a good balance between simplicity and accuracy (Taucer et al. 1991).

In non-linear dynamic analysis, the non-linear properties of the structure are considered as part of a time domain analysis. This approach is the most rigorous, and is required by some building codes for buildings of unusual configuration or of special importance. However, the calculated response can be very sensitive to the characteristics of the individual ground motion used as seismic input; therefore, several analyses are required using different ground motion records to achieve a reliable estimation of the probabilistic distribution of structural response.

Since the properties of the seismic response depend on the intensity, or severity, of the seismic shaking, a comprehensive assessment calls for numerous nonlinear dynamic analyses at various levels of intensity to represent different possible earthquake scenarios. This has led to the emergence of methods like the Incremental Dynamic Analysis (Bozorgnia and Bertero 2004).

\subsection{Geometric Nonlinearity}

For specification of nonlinear geometry of ODBS, concrete nonlinearity is added to material nonlinearity in this paper. Only steel nonlinearity for third member of ODBS is considered in this article's analysis. Steel, on the other hand, is linearly elastic up to a certain stress (called the proportional limit) after which it reaches yield point $\left(f_{y}\right)$ where the stress remains almost constant despite changes in strain. Beyond the yield point, the stress increases again with strain (strain hardening) up to the maximum stress (ultimate strength, $f_{u l t}$ ) when it decreases until failure at about a stress quite close to the yield strength.

Nonlinear static procedures use equivalent SDOF structural models and represent seismic ground motion with response spectra. Story drifts and component actions are related subsequently to the global demand parameter by the Pushover or capacity curves that are the basis of the nonlinear static procedures. Nonlinear dynamic analysis utilizes the combination of ground motion records with a detailed structural model, therefore is capable of producing results with relatively low uncertainty. In nonlinear dynamic analyses, the detailed structural model subjected to a groundmotion record produces estimates of component deformations for each degree of freedom in the model and the modal responses are combined using schemes such as the sum of squares square root.

Complete comparisons of the studied Retrofitted Frames in ANSYS program (version 15) with the Micro modeling structural element indicate that ODBS steel bracing RC frame has two yielding point that were related to main $\mathrm{RC}$ flexural frame and third steel member of ODBS. It's so useful for structures that are under Impact Loads and loads by high velocity specifically according to Fig. 2 of the previous page.

\section{Finite Element Models}

\subsection{Finite Element Modeling Procedure}

After doing the consecutive try and error, the possibility of FE models creation is provided for two models, flexural and X-bracing systems. Results verification is performed by more than $95 \%$ of convergence accuracy based on two models. After this double precision, comparative models were found the best parameters for simulation processing. Some parameters same as materials definition, element type, elastic constants, nonlinear properties, contact surface and other structural characteristics, are contributed in ODBS modeling and processing. The finite element analysis is performed in term of various investigations to obtain the results after ODBS modeling. As indicated in Fig. 4d, other verification is based on cracking analysis for two comparative models in $\mathrm{RC}$ frame by comparing the experimental results; the created cracks of two models were being as same as each other. The 3-D finite element deformed shapes are given in Fig. $4 \mathrm{a}-\mathrm{c}$ for each model.

The main Flexural $\mathrm{RC}$ frame is calibrated by results of experimental modeling of the same flexural frame and $\mathrm{X}$ -

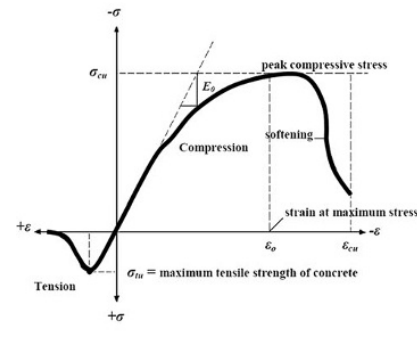

(a)

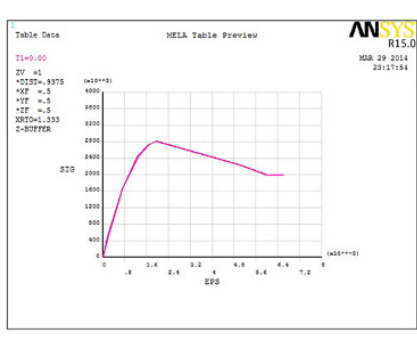

(b)

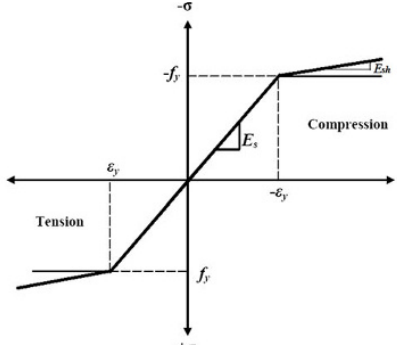

(c)

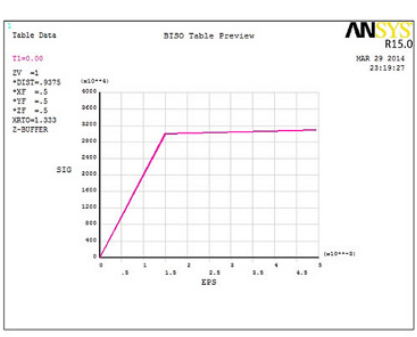

(d)

Fig. 3 Materials model properties, a parametric model for concrete; $\mathbf{b}$ concrete model definition in present research; $\mathbf{c}$ parametric model for steel; $\mathbf{d}$ steel model definition in present research. 
(a)

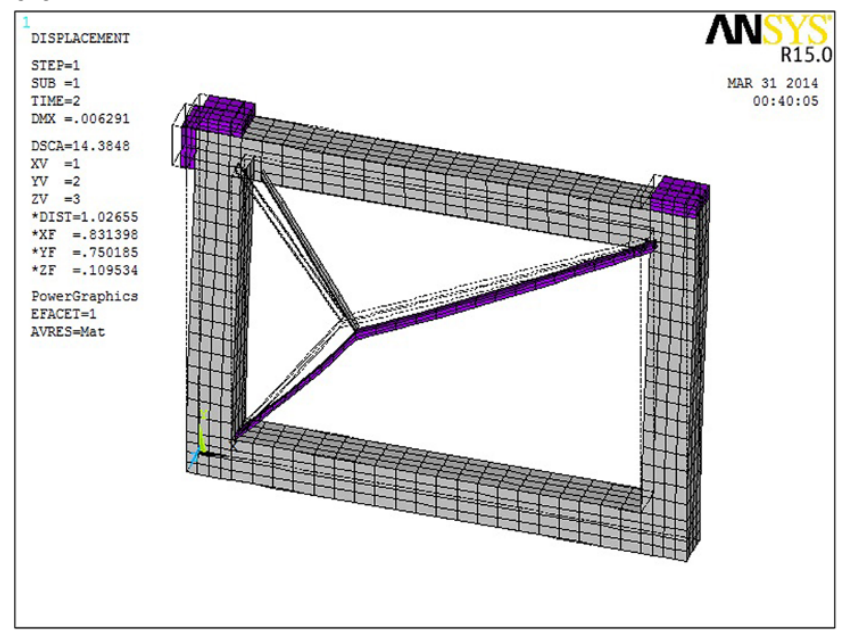

(c)

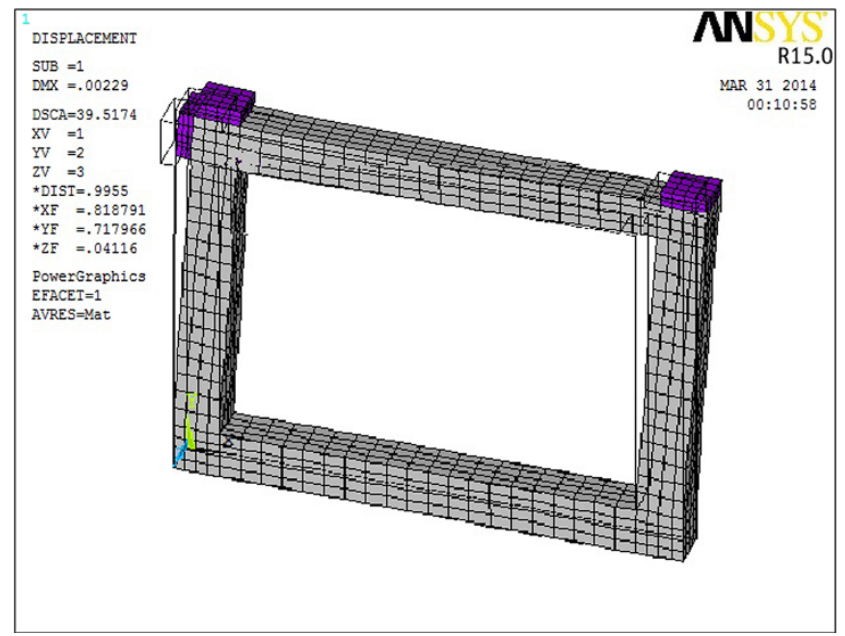

(b)

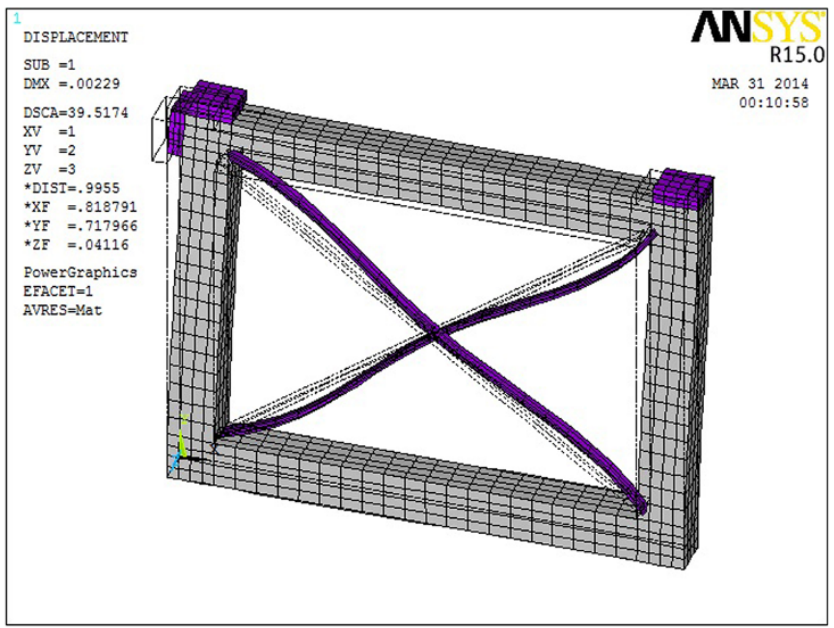

(d)

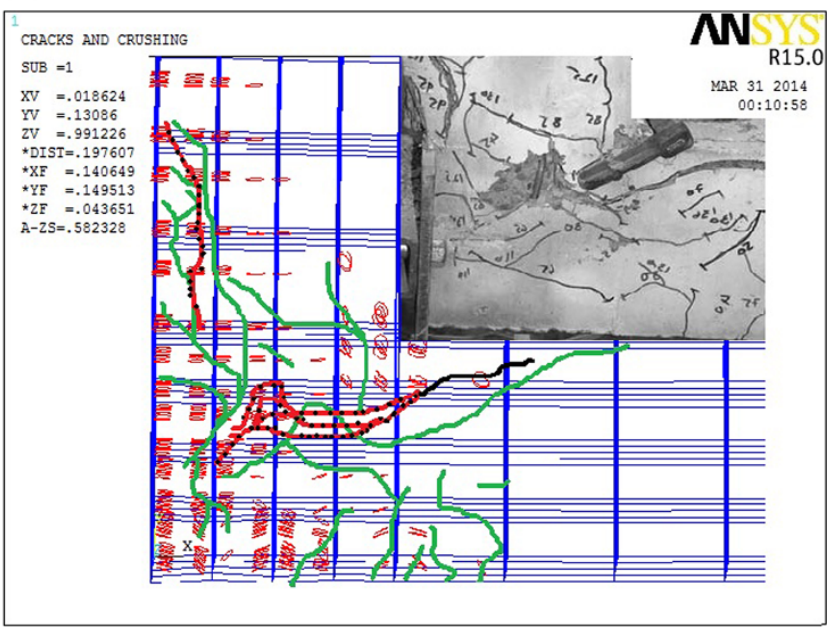

Fig. 4 Numerical model properties, a ODBS deformed shape; $\mathbf{b}$ X-Braced deformed shape; $\mathbf{c}$ flexural frame deformed shape and $\mathbf{d}$ flexural frame crushing comparison.

Braced frame that constructed in laboratory (Maheri and Hadjipour 2003).

\subsection{Comparison Between FE and Experimental Results}

As explained before, after performing the finite element 3-D modeling, for the next phase, the models were being analyzed and some results about them are obtained. The important status is concerned about results calibration for both of comparative models, flexural and X-braced frames where their results are indicated in Fig. 5, in the form of pushover diagrams calculated by nonlinear static analyses on reinforced concrete frame. The results are converged within the acceptance criteria for experimental and numerical investigations. As shown in Fig. 5, the flexural frame convergence is more than the x-braced frame, because in the existence of approximately modeling proceed in various elements such as gusset plates, expected length of reinforcement, steel brace section areas and also the other approximation are related to defining and modeling contact element. According the nonlinear static analysis, compared results of experimental and numerical models, have shown by Force-Displacement diagram and related control. Numerical modeling is base on exact modeling and Real parameters. This diagram shows that errors in modeling were minimized and convergence condition was satisfied.

As consequences from the geometric properties of ODBS, a diagonal eccentricity is the one important parameters affected on this system's behavior. So the different kinds of models are simulated and tested by various eccentricities. Optimum eccentricity from the viewpoint of geometric characteristics of ODBS is about $0.3-0.4$ for $\mathrm{e}_{1}$ and 0.5 for $e_{2}$. The $e_{2}$ eccentricity is concerned about geometric properties, position of members, angle of braces, height and span dimensions and etc. Increasing ductility is directly in relation with increasing eccentricity but some ingredients such as allowable drift, crack width and deflection are from limitations applying eccentricity $e_{1}$. However if the structural purpose be proportional to large amount of stiffness, the off-diagonality should be decreased, but for the purpose of high ductility it was inverse. Some comparative results of possible eccentricities are indicated in Fig. 6.

Figure 7 illustrates a typical mode of failure of the tested reinforced concrete frame with and without bracing systems 
Push-Over Curves fo Calibration of Flexural Frame in Finite Element Model (kN-m)

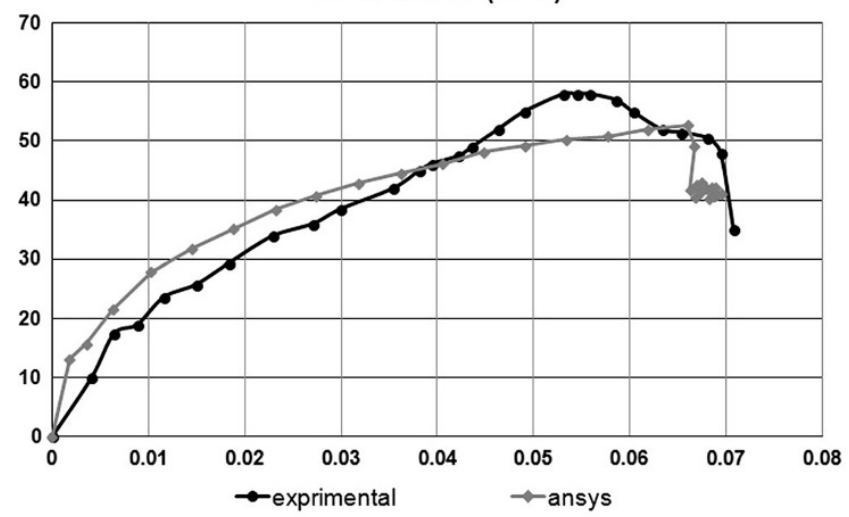

(a) Flexural frame calibration

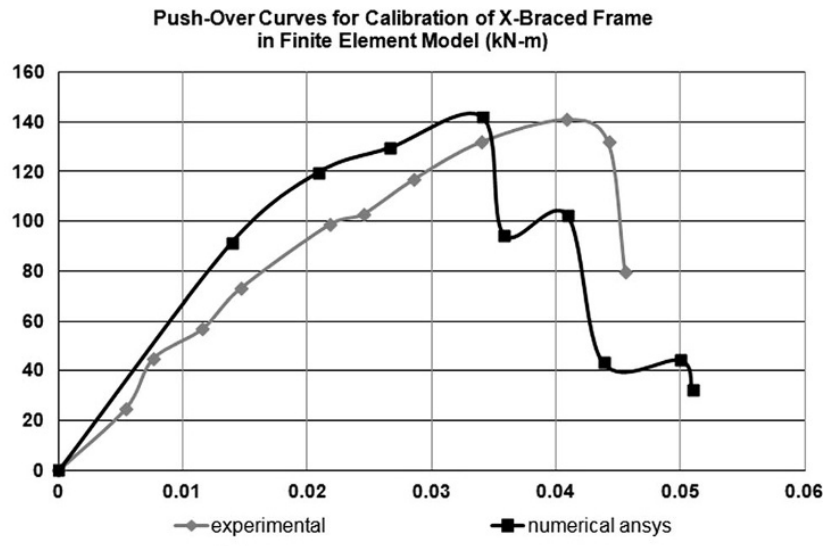

(b) X-braced frame calibration

Fig. 5 Comparison Flexural frame calibration (a) and X-braced frame calibration (b) deformed Frames Pushover curves for performing calibration process between ANSYS model's obtained results and experimental results.
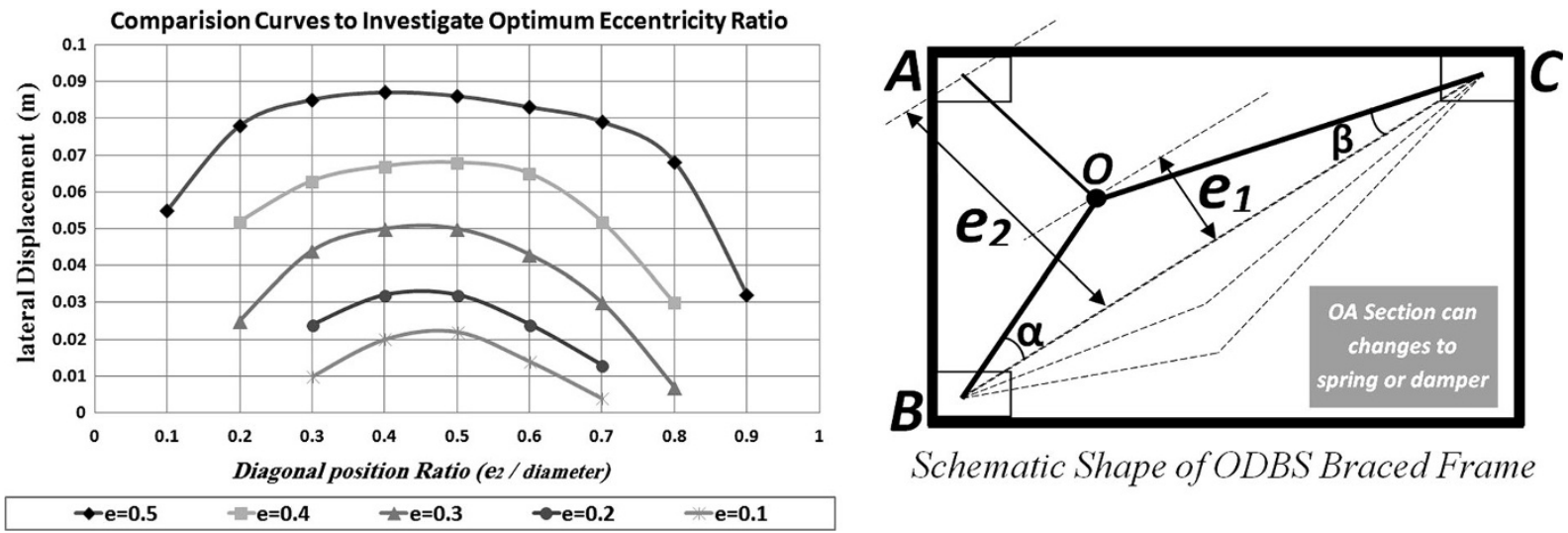

Schematic Shape of ODBS Braced Frame

Fig. 6 Obtained lateral displacement in term of different eccentricities for Off-Diagonal bracing system (left) and parametric shape of ODBS system (right).

under static push-over loading. A typical deformed shape from the FE model is also provided in right side of figures, which perfectly matches the actual mode of failure.

Figure 7 shows a front view of this modeled RC frame. In Fig. $7 \mathrm{a}$ and $\mathrm{b}$, the experimental and numerical force-displacement curves are compared for flexural frame and x-braced frame, respectively. Lateral displacements are measured at the base points at the top height of the frames. A comparison between these two figures shows the amount of calibration level in compare with the experimental modeling frames. The specific purpose of 3D finite element modeling is based upon the complex behavior of reinforced concrete nonlinearity and the geometric nonlinearity that applied for this paper.

The response modification factor ( $R$ factor) is the one of important factors for introducing the structural behavior specially to define ductility and stiffness of structures. To doing this aim, the separated calculations are performed to obtaining the factor of behaviour. Related force-displacement diagrams in form of bilinear pushover curves and the samples of finite element modeling are shown also in left side of Fig. 7.

After generating the pushover curves, the response modification factors are obtained for each model. The highest ductility and the large amount of energy dissipation are from ODBS system results.

\subsection{The Response Modification Factor for ODBS Braced RC Frame}

According to Fig. 8; Table 1 and by considering Pushover curves, to calculate the response modification factor, some basic formula is needed. As shown in Fig. 8, usually real nonlinear behaviour is idealized by a bilinear elastic perfectly plastic relationship. The yield base shear coefficient of structure is shown by $V_{y}$ and the yield displacement is $\Delta_{y}$. In this figure, $V_{e}$ corresponds to the elastic response strength of the structure. The maximum base shear ratio in an elastic perfectly behaviour is $\Delta_{y}$ (Uang 1991). The ratio of maximum base shear coefficient considering elastic behaviour $V_{e}$ to maximum base shear coefficient in elastic perfectly behaviour $V_{y}$ is called force reduction factor.

$$
R=R_{\mu} \cdot R_{s} \cdot Y, R_{\mu}=V_{e} / V_{y}
$$

The overstrength factor is defined as the ratio of maximum base shear coefficient in actual behaviour $V_{y}$ to first significant yield strength in structure $V_{s}$.

$$
R_{s}=V_{y} / V_{s}=\Omega
$$

The concept of overstrength, redundancy and ductility, which are used to scale down the earthquake forces need to 

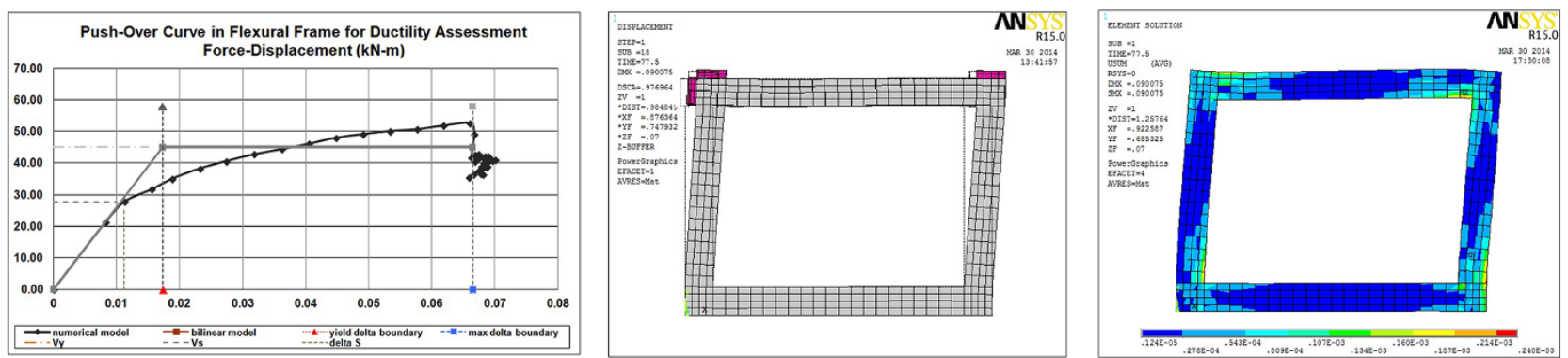

(a) Force-Displacement curve of Flexural frame and deformed shape and sum of elastic \& plastic strain contour.
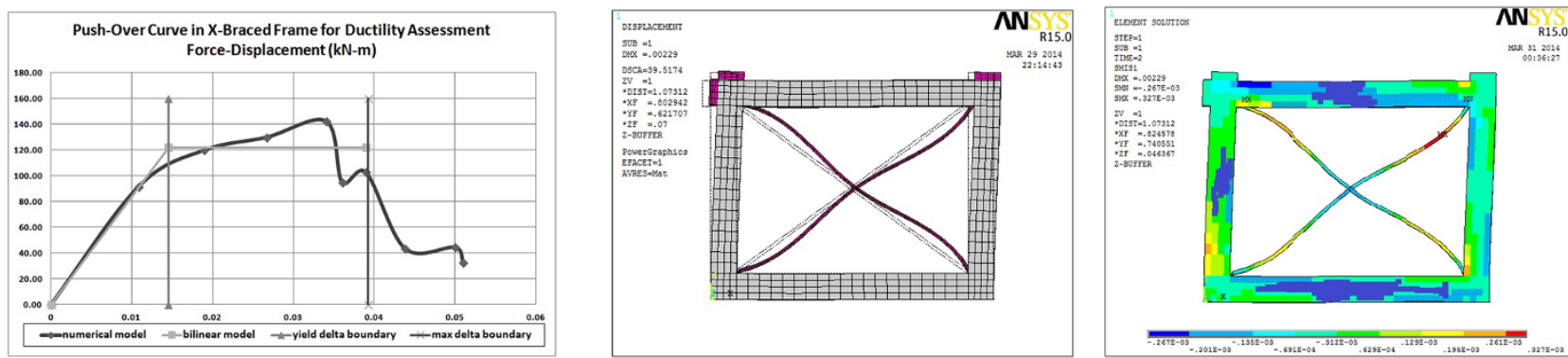

(b) Force-Displacement curve of X-Braced frame and deformed shape and sum of elastic \& plastic strain contour.
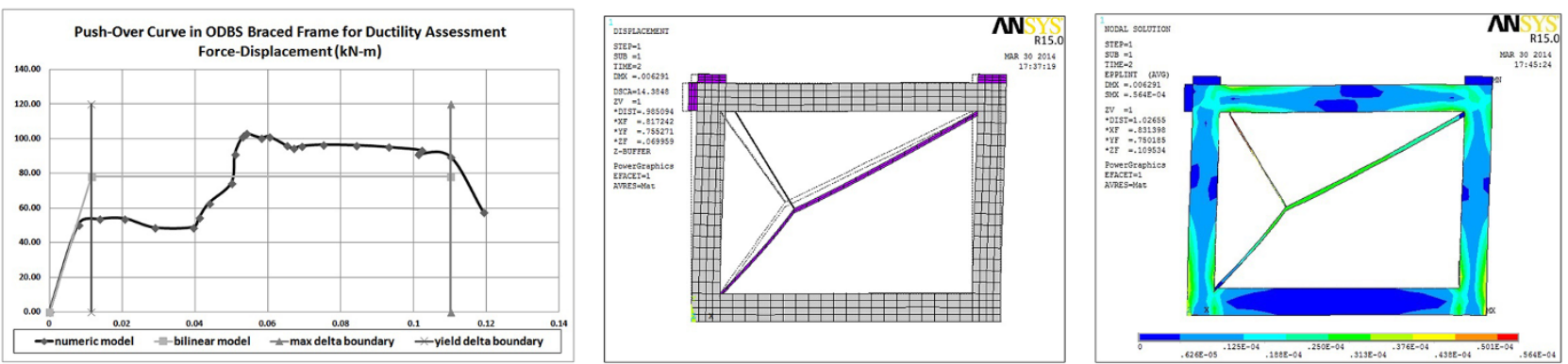

(c) Force-Displacement curve of steel ODBS braced frame and deformed shape and sum of elastic \& plastic strain contour respectively.

Fig. 7 Pushover Diagrams by specified bilinear equivalent curves in various Types of a RC Flexural Frame and b X- Steel Braced RC Flexural Frame and $\mathbf{c}$ ODBS Steel Braced RC flexural Frame (Plus results of simulated models in ANSYS).

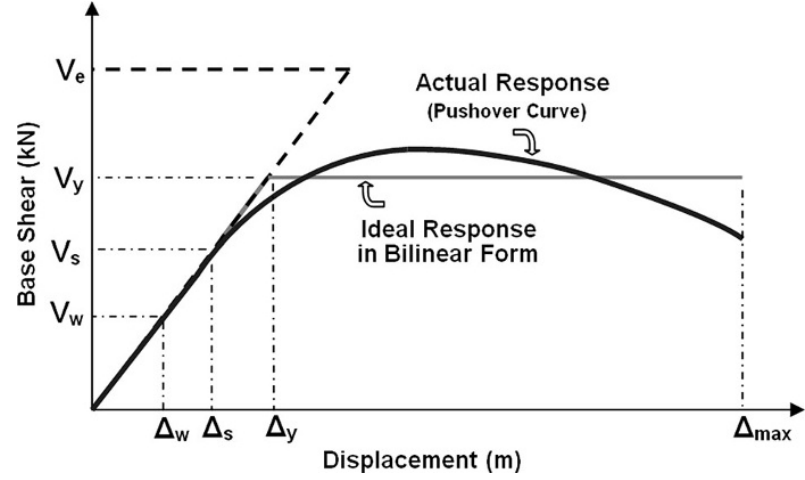

Fig. 8 Response modification factor evaluation along Pushover curve and its equivalent bilinear EPP curve.

be clearly defined and expressed in quantifiable terms. To design for allowable stress method, the design codes decrease design loads from $V_{s}$ to $V_{w}$. This decrease is done by allowable stress factor $Y$ (Uang 1991).

$$
Y=V_{s} / V_{w}
$$

The range of this factor is about 1.4-1.5. In this paper allowable stress factor $Y$ was considered as 1.4 (ATC 1995a).

$$
\begin{aligned}
& R\left(R_{w}\right)=\left(V_{e} / V_{y}\right) \cdot\left(V_{y} / V_{s}\right) \cdot\left(V_{s} / V_{w}\right)=\left(V_{e} / V_{w}\right) \\
& R=R_{\mu} \cdot R_{s}=\left(V_{e} / V_{s}\right)
\end{aligned}
$$

Equation (4), shows the seismic response modification factor $\left(R_{w}\right)$ in ultimate strength design method. Also, Eq. (5), indicates seismic response modification factor in allowable stress design method. Structural ductility, $\mu$, is defined in terms of maximum structural drift $\left(\Delta_{\max }\right)$ and the displacement corresponding to the idealized yield strength $\left(\Delta_{y}\right)$, as given in Eq. (6).

$$
\mu=\Delta_{\max } / \Delta_{y}
$$

The response modification factor $(R)$ is included of the inherent ductility and ductility and overstrength effects of a structure and the difference in the design methods and limitations about related manual. Also Ductility reduction factor $R \mu$ is a function of both of the characteristics of the structure including ductility, damping and fundamental 
Table 1 The maximum drift values (regardless of drift limitations) and ductility and $R$ factor for floor.

\begin{tabular}{c|c|c|c|c|c|c|c|c|c|c|}
\hline Model & $\Delta_{y}(\mathrm{~m})$ & $\Delta_{\max }(\mathrm{m})$ & $\Delta_{s}(\mathrm{~m})$ & $\Delta_{w}(\mathrm{~m})$ & $V_{e}(\mathrm{~kg})$ & $V_{y}(\mathrm{~kg})$ & $V_{s}(\mathrm{~kg})$ & $V_{w}(\mathrm{~kg})$ & $\mu$ & $R$ \\
\hline \hline $\begin{array}{c}\text { flexural RC } \\
\text { frame) } \mathrm{F}_{1}\end{array}$ & 0.0173 & 0.0665 & 0.0112 & 0.067 & 17,272 & 4,500 & 2,875 & 1,740 & 3.84 & 9.92 \\
\hline $\begin{array}{c}\text { (X-Braced } \\
\text { frame) } \mathrm{F}_{\mathrm{X}}\end{array}$ & 0.0103 & 0.039 & 0.0058 & 0.0547 & 33,034 & 12,200 & 9,147 & 5,480 & 2.69 & 6.04 \\
\hline $\begin{array}{c}\text { (ODBS- } \\
\text { Braced } \\
\text { frame) } \\
\mathrm{F}_{\text {ODBS }}\end{array}$ & 0.0125 & 0.1101 & 0.0082 & 0.0781 & 26,177 & 7,800 & 5,032 & 3,012 & 9.58 & 23.2 \\
\hline
\end{tabular}

period of vibration $(T)$, and the characteristics of earthquake ground motion. Figure 8 explains the schematic behaviour and its corresponding parameters to calculating response modification factor.

Where $R_{s}$ is the overstrength factor and $\mathrm{Y}$ is termed the allowable stress factor (Maheri and Akbari 2003).

The results indicate the highest amount of response modification factor $(R)$ is obtained for ODBS proportional to the other systems. By considering the presented formulation, the obtained results are gathered in Table 1 . The $R$ factor for ODBS is same as the system of displacement and vibration control, particularly same as the systems isolator and friction dampers. The author has other research paper about the ODBS innovation considering a new friction dampers substituted by third member. The system of composed damper-spring can be a suitable subject for further researches.

\subsection{Crack Evaluation Through Finite Element Models}

The next step of ODBS evaluation is concerned about control and compare of the existing and progressive cracks at the different time steps by the various FE models. Before any concluding for ODBS model, at the first, the flexural and $\mathrm{X}$-braced models are compared along their cracking pattern with experimental models. To verifying the numerical model's cracks for this meaning, all happened cracks at the last phase of loading are represented and then they are compared with cracks on experimental model. Verifying assessments are performed on cracks place, directions, cracks width, time of occurrence and their geometry, that, they are matched by experimental results and fortunately they were similar up to $85 \%$. Figure 9 indicates comparative cracks in flexural and X-bracing frames.

After confirming the compared cracks, for the next stage, the crack analysis is performed on ODBS braced RC frame for further assessments. The ODBS braced frame is analyzed through 94 time steps by displacement control method. The cracking analysis is checked for three times in steps of 28, 65 and 92 from imposed displacement of ODBS model. The reasons for selecting the mentioned time steps along main cracking investigation are at first, effective parameters about crack development and performing plastic hinges along different rotations and at second existed deformation in steel bracing members concerned about important stage of behavior such as yielding and plastic behavior for steel material.

As observed in Fig. 10 in 28th time step, the lateral displacement level is notated about $23 \mathrm{~mm}$ that it was equivalent to imposing $51 \mathrm{kN}$ lateral loads on the ODBS braced frame. Until this step only the flexural cracks were observable and have not shown the major weakness along the structural concrete. Almost the third member is yielded and its behavior is investigated simultaneously with plastic behavior, but entirely does not exhibit any plastic behavior till this stage.

The time step 65, where flexural cracks developed densely and the shear cracks are started in some regions. Along 65th step, the lateral displacement is reached to $37 \mathrm{~mm}$ in upper level of the ODBS braced frame that this stage's displacement was equivalent to $101.5 \mathrm{kN}$ in term of lateral force. Most of the longitudinal reinforcements were yielded and the relevant $\mathrm{RC}$ section is experienced the nonlinear strain perpendicular to section's surface. Members near the diagonal axis are yielded and also prepared to endure the large strain. The third member of steel bracing system achieved the maximum deformation and its plastic behavior was clearly obvious. And also some points of RC frame are experienced the plastic deformation. Crack pattern of step 65 is indicated in Fig. 11.

According to last considered time step, 92th step, adjacent to the collapse limit, the upper level's lateral displacement of the ODBS braced frame is reached about $100 \mathrm{~mm}$ that it was equivalent to $96.43 \mathrm{kN}$ in term of lateral force. The second stage of yielding phenomenon and the second stage of plastic behaviour are created within the steps of 65-92 and maximized the displacement according to the last pages schematic shape. In this stage, sustainable lateral force is lower than the last stage because of plastic behavior happened in both of RC frame and steel ODBS members, conjugately. In this last stage many plastic zones are performed on the RC frame and the plastic strain is observed along three steel members. The third member of ODBS is given necking and lost its strength entirely. Crack pattern of step 92 is indicated in Fig. 12.

Through the stages of consideration, the ODBS braced RC frame is experienced various behaviours as elastic, elasticplastic, secondary elastic, secondary elastic-plastic and plastic, then it was in threshold of collapse and also bracing 
(a)

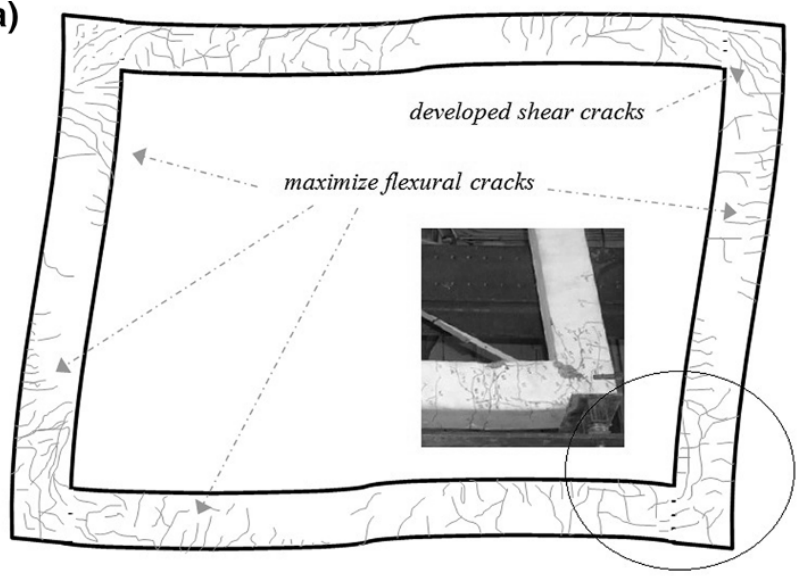

(b)

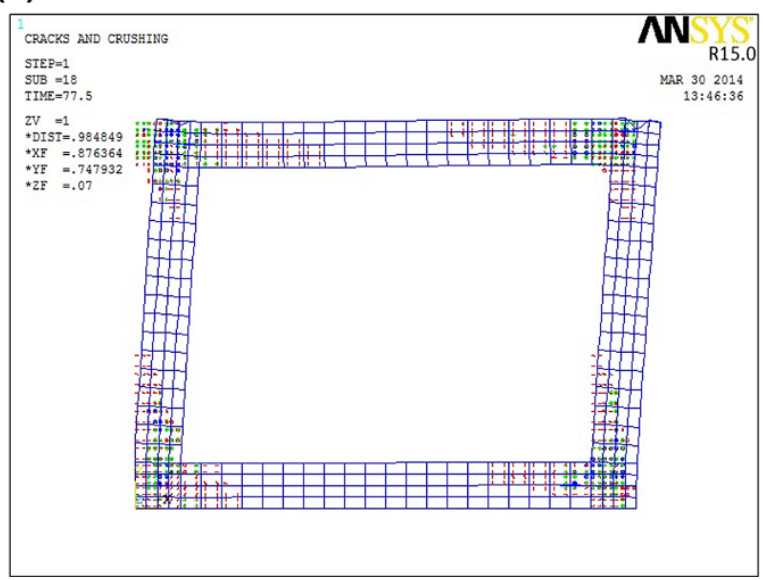

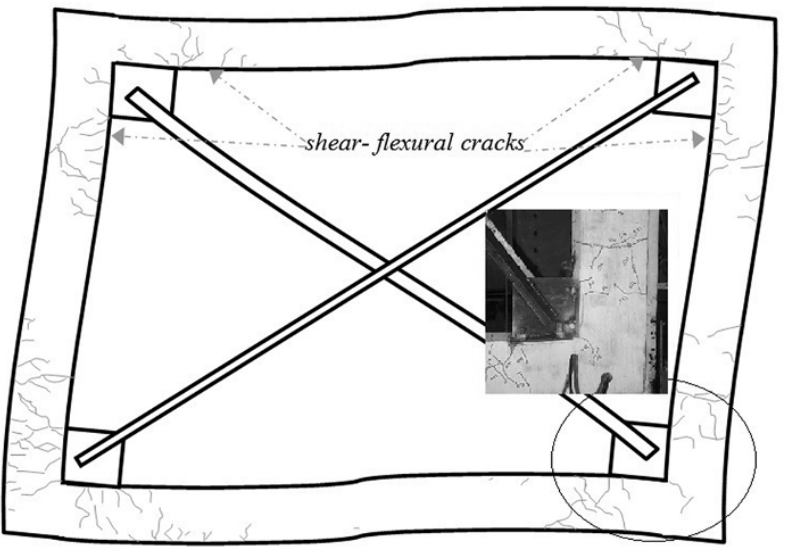

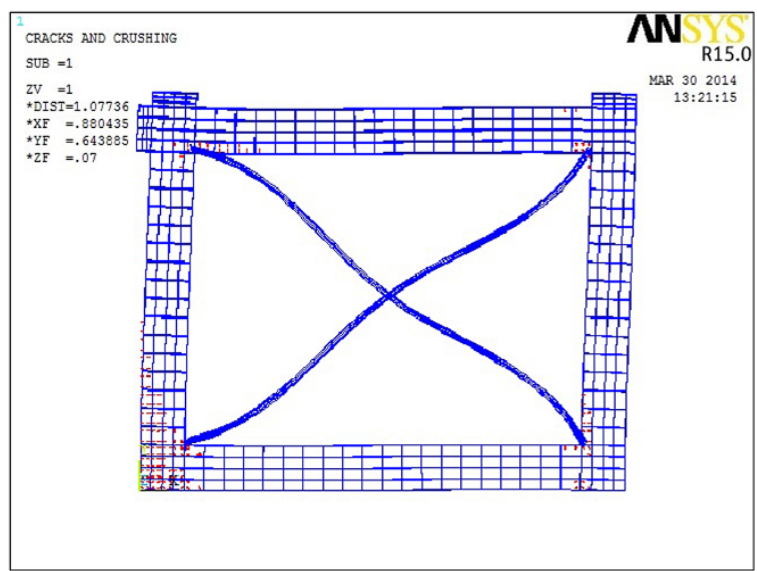

Fig. 9 Comparison between experimental and FE crack patterns for flexural frame (left) and x-braced frame; a happened cracks in experimental models (Maheri et al. 2006; Youssefa et al. 2007) and b happened cracks in numerical models.
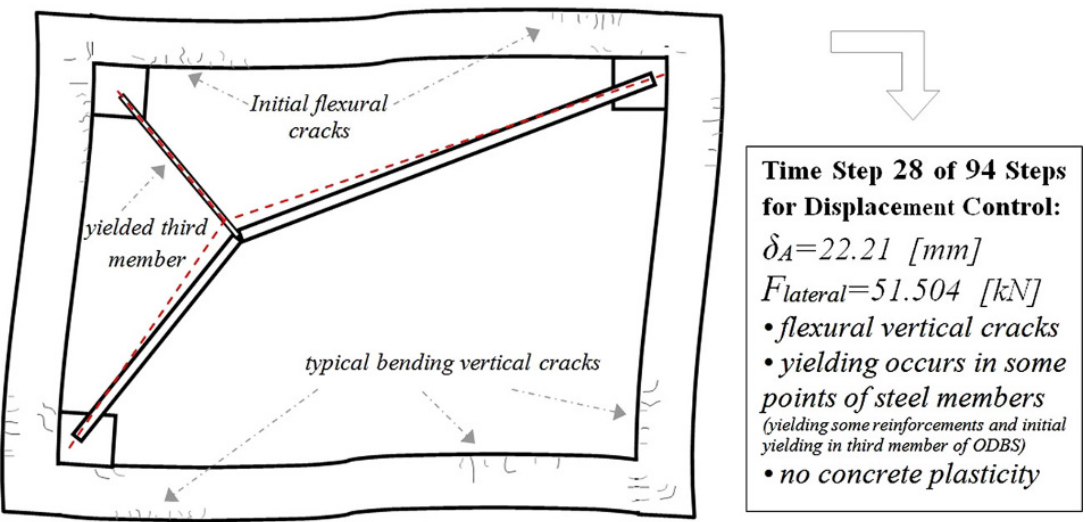

Fig. 10 Flexural and shear cracks development at the front side of the ODBS braced frame, deformed shape and cracks pattern observed at step 28.

members are formed parallel to each other and they were on diagonal axis. In this position, if the diagonal members lost their strength, then the whole frame was being collapsed.

Comparison between ODBS and other frames is not only about high ductility results of ODBS proportional to flexural and specially $\mathrm{x}$-bracing system, but also the ODBS braced frame entirely used from flexural capacity of RC frame.
Whereas the $\mathrm{x}$-braced RC frame did not use more than 20 percent from its flexural capacity. So the energy dissipation in the system of flexural and x-braced frame is lower than the ODBS braced frame. Figure 13 indicates the behaviour of ODBS for time step 28 in ANSYS finite element software. In another figure the plastic behaviour is concerned about concrete strain energy as shown. 


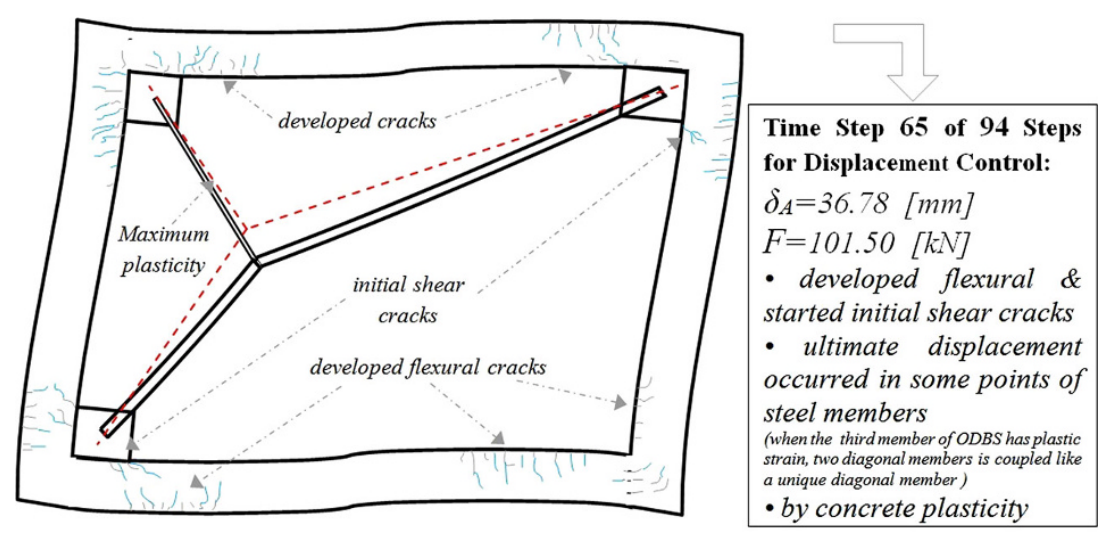

Fig. 11 Flexural and shear cracks development at the front side of the ODBS braced frame, deformed shape and cracks pattern observed at step 65.

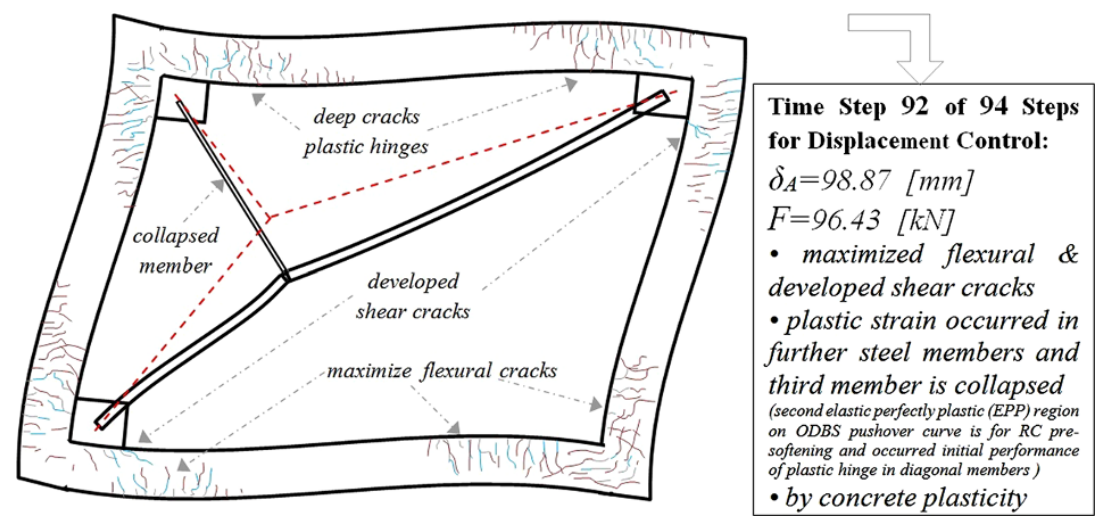

Fig. 12 Flexural and shear cracks development at the front side of the ODBS braced frame, deformed shape and cracks pattern observed at step 92 just before the collapse.

\section{Numerical Models}

In the next phase, various systems of bracing frame by different stories is studied for further investigation of ODBS compare with the other types of bracing. Figure 14 shows the different models under nonlinear dynamic analysis. Therefore the present model had the greater dimensions and also more stories, then using ANSYS program for these properties simulation was impossible, so for further modeling by raising height, spans and number of stories the SAP2000 (2010) software is used to continuing this research paper for optimizing the time consuming. This software is adapted to advanced analysis in the type of static and dynamic.

Almost, this software is calibrated and scaled by experimental results according to last scaling for ANSYS software. Finally, the results are verified for flexural and x-braced frame as recent models. The results of calibration along the numerical and experimental models are indicated in Fig. 15. By confirming the modeling proceeds in recent software, the pushover curves are drawn in term of force-displacement as indicated. These comparative results explained the convergence accuracy higher than $92 \%$ between recorded numerical results and recorded experimental results.

\section{Time History Analysis Methodology}

\subsection{Time History Records}

Nonlinear dynamic analysis for this research has been imposed of three types of frame that mentioned before. Tabas, Naghan and Elcentro, the three scaled records of ground motion are considered for the dynamic time history analysis. Simplified form of these records is evaluated for response spectrum, so performed response spectrum analysis on ODBS to study about modal characteristics. Earthquake characteristics are indicated in Table 2. The load cases are defined at several conditions. Zero condition is concerned about applying the dead load and live load. Secondary condition is concerned about static and dynamic nonlinear analysis.

Macro modeling method was used to analyze the nonlinear behaviour of reinforced concrete frame strengthened by steel bracing system (macro element by lowest accuracy related to micro modeling elements). The model was calibrated using existing laboratory work results and then, larger number of floors and openings were analyzed. The SAP2000 (2010) software was employed to modeling the reinforced concrete frame braced with ODBS system. Dynamic time history analysis is done for modeling high rise concrete frames by 


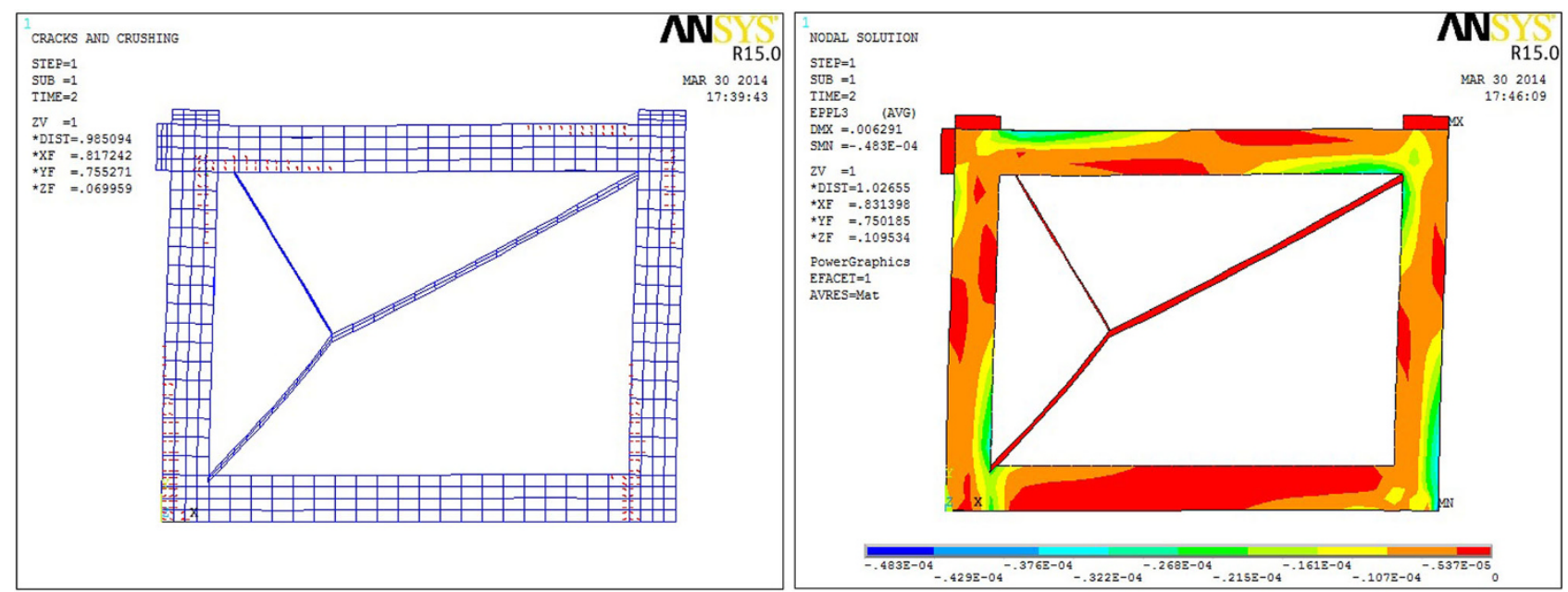

Fig. 13 FE crack pattern of ODBS braced frame obtained in step 28 of imposing displacement (left) and plastic strain energy contour along the RC frame (right).

(a)

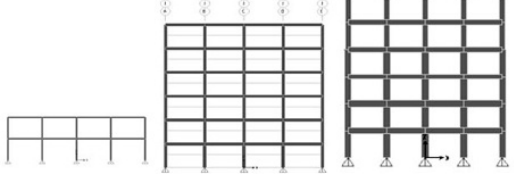

(b)

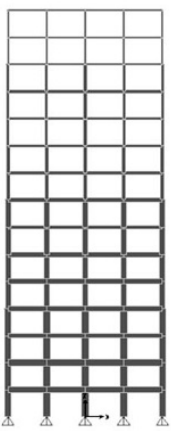

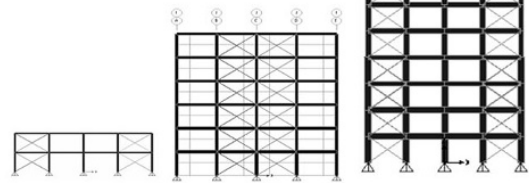

(c)

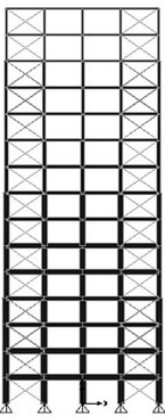

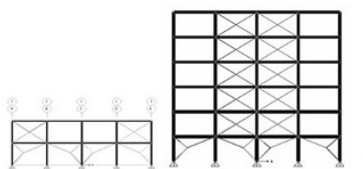

Fig. 14 Numerical models by various load bearing systems used for dynamic analysis by types of two-story, six-story and fifteenstory models respectively from left to right for flexural frame (a), x-braced frame (b) and ODBS braced frame (c).
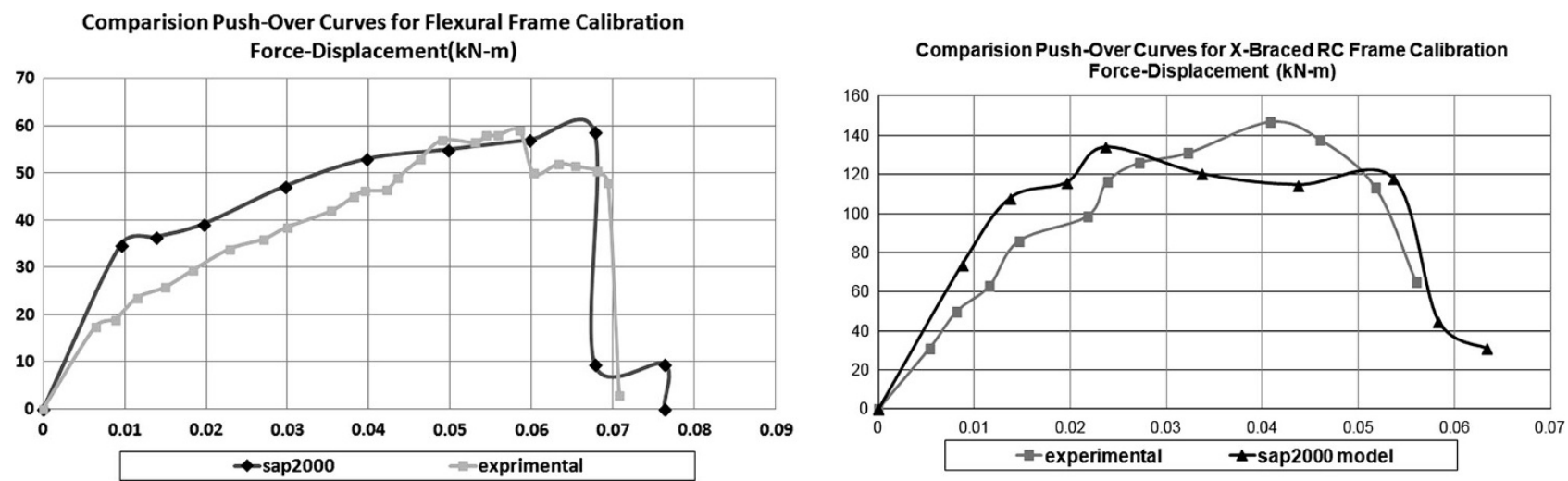

Fig. 15 Convergence between SAP2000 (2010) numerical results and experimental results for verifying the calibration process in term of their pushover curves.

increased height and width. Time history analysis using earthquake accelerograms is one of the suggested methods by most regulations to investigate the seismic behaviour of structures. In this study is used the three accelerograms of Naghan, Tabas and Elcentro. Their general characteristics are listed in Table 2.

The various maximum ground acceleration after scaling is set to $0.3 \mathrm{~g}$. Three groups of records are selected based on two parameters; the closest distance to a fault rupture surface [greater than $50 \mathrm{~km}$ (far field), nearer than $10 \mathrm{~km}$ (near fault)] and the moment magnitude in every scales (Berberian 1977and Jamison et al. 2000). The other characteristics of the real accelerograms such as directivity, fault mechanism, and etc. are the same. The peak ground acceleration of all accelerograms is greater than $0.1 \mathrm{~g}$. These accelerograms are selected from strong ground motion records. The specifications and classification of each group before doing matching procedure are tabulated in Table 2. 
Table 2 Characteristics of scaled accelerograms used for time history analysis.

\begin{tabular}{|c|c|c|c|c|c|c|c|c|c|}
\hline \multirow[t]{2}{*}{ Records } & \multirow{2}{*}{$\begin{array}{c}\text { Duration } \\
\text { (s) }\end{array}$} & \multirow{2}{*}{$\begin{array}{c}\text { PGA } \\
\mathrm{m} / \mathrm{sec}^{2}\end{array}$} & \multirow{2}{*}{$\begin{array}{c}\text { Time } \\
\text { Step(s) }\end{array}$} & \multirow{2}{*}{$\begin{array}{l}\text { Country } \\
\text { of event }\end{array}$} & \multirow{2}{*}{$\begin{array}{c}\text { Date of } \\
\text { event }\end{array}$} & \multirow[t]{2}{*}{ Station } & \multirow[t]{2}{*}{ Position } & \multicolumn{2}{|c|}{ Components } \\
\hline & & & & & & & & Latitude & Longitude \\
\hline Tabas & 50 & 3.42 & 0.01 & Iran & $1978 / 09 / 16$ & Deyhook & $\begin{array}{l}33.3^{\prime} \mathrm{N} \\
57.52^{\prime} \mathrm{E}\end{array}$ & 3.27 & 4.1 \\
\hline Naghan & 5 & 7.09 & 0.001 & Iran & $1977 / 04 / 06$ & Central & $\begin{array}{r}31.98^{\prime} \mathrm{N} \\
50.68^{\prime} \mathrm{E}\end{array}$ & 7.61 & 7.61 \\
\hline Elcentro & 53.7 & 3.49 & 0.01 & USA & $1940 / 05 / 18$ & E06 array & $\begin{array}{c}32.44^{\prime} \mathrm{N} \\
115.3^{\prime} \mathrm{W}\end{array}$ & 3.35 & 4.03 \\
\hline
\end{tabular}

(a)

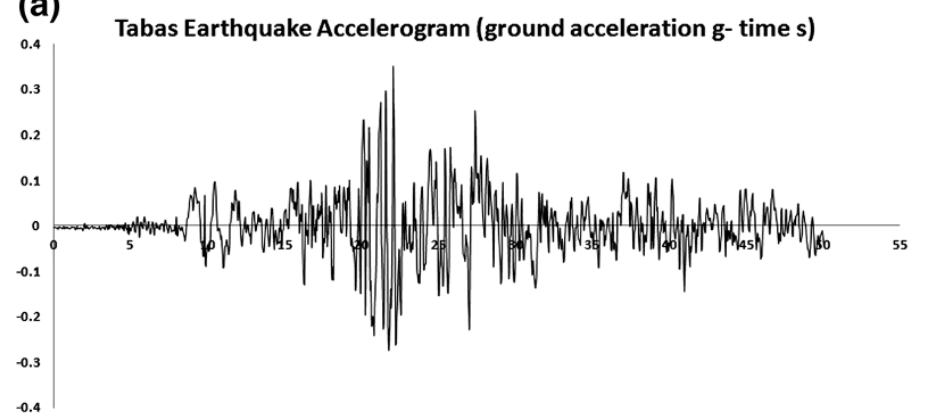

(b)

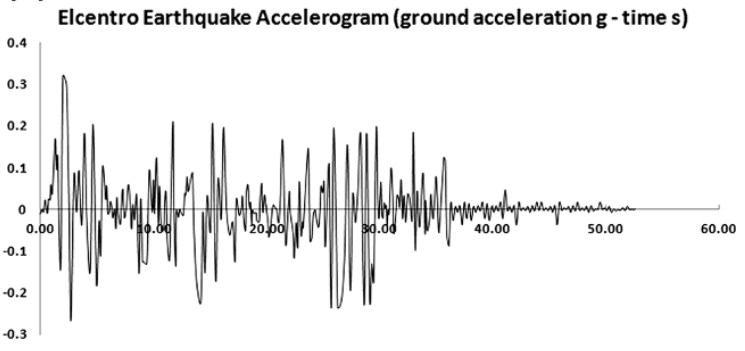

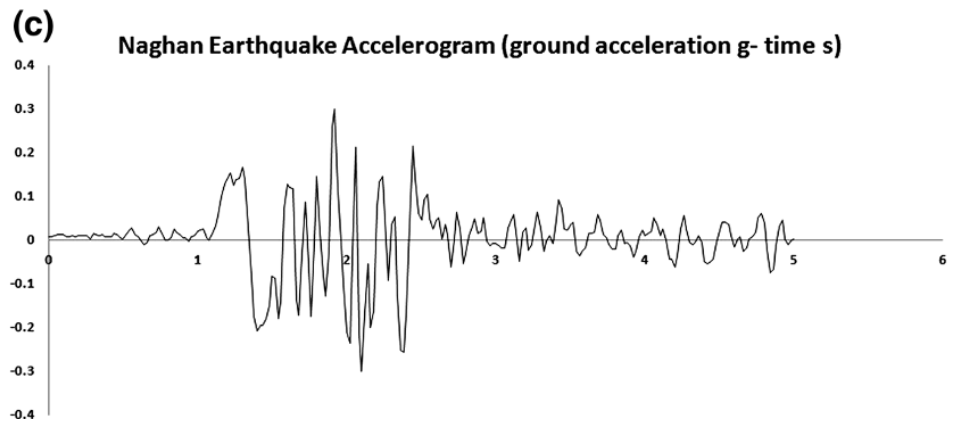

Fig. 16 Scaled ground acceleration used for time history analysis; a Tabas record accelerogram in scaled form, b Elcentro record accelerogram in scaled form and $\mathbf{c}$ Naghan record accelerogram in scaled form.

Accelerograms of various time histories, the earthquake excitations, in the scaled form are indicated in Fig. 16 as below.

\subsection{Structural Modeling}

Since the characteristics of these earthquakes are different from other places, they have to be scaled to a scale before using them for non-linear dynamic analyses of the studied models. To scale accelerograms using UBC-97 method, the values of natural oscillation period were initially calculated for three models. These three models included the models with three spans and 2, 6, and 15 floors. Models were divided to three groups of short, medium, and tall buildings and their natural period were considered to be in three categories of short, medium, and long periods (Razavian Amrei et al. 2011). Models dimensions have considered $3 \mathrm{~m}$ for height of stories and $4 \mathrm{~m}$ for uniform spans length. Suitable structural periods were selected to be smaller than $1.5 \mathrm{~T} .^{1}$ In the next stage, the acceleration spectrum were determined for all three accelerograms and knowing the spectrum suggested by regulations, the ratio of regulation spectrum to

\footnotetext{
$\overline{1}$ The major vibration's period of models.
}

acceleration spectrum of recent accelerograms were found to vary from 0.2 to $1.5 \mathrm{~T}$. The arithmetic averages of the ratios were calculated for this range. In addition, scale factors were also investigated for taller buildings. Longitudinal and transverse reinforcements, characteristics and dimensions of three models flexural, $\mathrm{x}$-braced and ODBS frame are assigned according to Tables 3, 4 and 5. The assigned plastic hinges at capable plastic points and also the acceptance criteria for rotational and translational displacements are defined to models as Tables 3,4 and 5. The design criteria to selecting beam and column dimensions are corresponded to linear equivalent static analysis. Next analyses are considered for models and sections verification to doing their works properly.

According to the last table, the design sections of reinforced concrete frame and steel brace members are shown as below. The reinforced concrete sections are selected from 5 types. Each stories column is considered corresponding to Fig. 17 (left). Designed sections according to ACI manual are from maximum stress ratio or in the other word according to optimum state of strength and ductility. The ODBS sections are indicated in Fig. 17 (right). The schematic model of ODBS braced RC frame is presented in term 
Table 3 Design sections characteristics and component properties for two-story frame's members.

\begin{tabular}{|c|c|c|c|c|c|c|}
\hline Components & Floor & Type & $\begin{array}{l}\text { Dimensions } \\
(b \times h) \\
\end{array}$ & Bars and Stirrups & Hinges & $\begin{array}{c}\text { Acceptance criteria/ } \\
\text { type }\end{array}$ \\
\hline \multirow[t]{2}{*}{ Beams } & First floor & & $\begin{array}{l}\text { Rectangular } \\
25 \times 25(\mathrm{~cm})\end{array}$ & $\begin{array}{c}3 \varnothing 18 \varnothing 8 \\
\text { @ } 10,20 \mathrm{~cm} \text { (top } \\
\text { \&bottom) }\end{array}$ & Flexural (M3) & $\begin{array}{l}0.01 \text { rad plastic } \\
\text { rotation }\end{array}$ \\
\hline & Second floor & & $\begin{array}{l}\text { Rectangular } \\
25 \times 20(\mathrm{~cm})\end{array}$ & $\begin{array}{c}3 \varnothing 16 \varnothing 8 \\
@ 10,20 \mathrm{~cm} \text { (top } \\
\text { \&bottom) }\end{array}$ & Flexural (M3) & $\begin{array}{l}0.01 \text { rad plastic } \\
\text { rotation }\end{array}$ \\
\hline \multirow[t]{2}{*}{ Columns } & First floor & & $\begin{array}{l}\text { Rectangular } \\
30 \times 30(\mathrm{~cm})\end{array}$ & $\begin{array}{l}8 \varnothing 18 \varnothing 8 \\
\text { (a) } 10,20 \mathrm{~cm}\end{array}$ & $\begin{array}{c}\text { Flexural + Axial }(\mathrm{P}- \\
\mathrm{M} 3)\end{array}$ & $\begin{array}{c}0.012 \text { rad plastic } \\
\text { rotation }\end{array}$ \\
\hline & Second floor & & $\begin{array}{l}\text { Rectangular } \\
25 \times 25(\mathrm{~cm})\end{array}$ & $\begin{array}{l}8 \varnothing 16 \varnothing 8 \\
@ 10,20 \mathrm{~cm}\end{array}$ & $\begin{array}{c}\text { Flexural + Axial (P- } \\
\text { M3) }\end{array}$ & $\begin{array}{c}0.012 \text { rad plastic } \\
\text { rotation }\end{array}$ \\
\hline \multirow[t]{4}{*}{ Braces } & First floor & $\mathrm{X}$ & $\begin{array}{c}\text { Box } 8 \times 8 \times 0.5 \\
(\mathrm{~cm})\end{array}$ & - & Axial (P) & $\begin{array}{c}7 \Delta_{\mathrm{T}} \\
\text { Plastic deformation }\end{array}$ \\
\hline & Second floor & & $\begin{array}{c}\text { Box } 8 \times 8 \times 0.5 \\
(\mathrm{~cm})\end{array}$ & - & Axial (P) & $\begin{array}{c}7 \Delta_{\mathrm{T}} \\
\text { Plastic deformation }\end{array}$ \\
\hline & First floor & ODBS & $\begin{array}{c}8 \times 8 \times 0.5: 1,2 \\
(\text { Members }) \\
2 \times 2 \times 0.3: 3 \\
(\text { Members })\end{array}$ & - & Axial (P) & $\begin{array}{l}7 \Delta_{\mathrm{T}} \\
9 \Delta_{\mathrm{T}}\end{array}$ \\
\hline & Second floor & & $\begin{array}{c}8 \times 8 \times 0.5: 1,2 \\
(\text { Members }) \\
2 \times 2 \times 0.3: 3 \\
(\text { Members })\end{array}$ & - & Axial (P) & $\begin{array}{r}7 \Delta_{\mathrm{T}} \\
9 \Delta_{\mathrm{T}}\end{array}$ \\
\hline
\end{tabular}

of using spring element instead of steel element for third member of bracing system. The composed form of ODBS by damper, spring and steel bracing member could be state of the art characteristics for lateral bearing system with passive energy dissipation.

One of the important analyses for investigating the seismic behaviour of a structure is the time history analysis. So for supplementary analysis, the nonlinear dynamic analysis (NDA) is performed for various time histories.

\section{Analysis for Results}

\subsection{Inter-Story Drift Investigation}

The obtained inter-story drift results are indicated the amount of dissipated displacement and energy dissipation is increased in a system by more ductility and deformability. The flexural frame is contributed more than $\mathrm{x}$-braced frame in strain energy absorption, because of its ductile characteristics. Construction of ODBS system is divided by two patterns. First, adding off-diagonal steel brace to the first story RC frame, since the $\mathrm{x}$-brace system is used for other stories (composed bracing system by ODBS at first story and $\mathrm{x}$-bracing system for other stories). As second pattern, adding the off-diagonal bracing system to all stories of RC frame (without any composed bracing system). If the system of bracing selected from first pattern, the first story treats as a ductile system and other stories were being treat as a semi rigid body.

The first pattern advantage was a performance same as base isolation system that it is absorbed the vibrations of ground motion and the other stories had a minimum proportional displacement (limits of inter-story drift is checked always). What is too important by this pattern is the limitation of first inter-story's drift in term of seismic manuals. This system is behaved exclusively, if the regarded drifts being in use. The decision making about second pattern is too important because of its complicated behaviour. When the ODBS is performed in all stories, the energy dissipation potential is created in each story of the structure. By considering the basic lateral resisting system along flexural frame for ODBS system, by adding steel braces, the lateral displacement decreased strongly at each story. In the other word each story equipped by a type of damper and vibrations are controlled and dissipated specially for stories up to fifth or sixth.

One another investigation is about recorded displacements in special base points. The base points are usually selected along the point nearest to center of mass and center of lateral stiffness. Some single base points are chosen at the last floor's upper level, such as for pushover analysis, on each type of models, these points were monitored along the incremental static loads. Also in dynamic time history analysis, the central base points in each story are defined and monitored to control proportional displacement and/or in the other word, inter-story drift controlling. 
Table 4 Design sections characteristics and component properties for six-story frame's members.

\begin{tabular}{|c|c|c|c|c|c|c|}
\hline Components & Floor & Type & $\begin{array}{l}\text { Dimensions } \\
\quad(b \times h)\end{array}$ & Bars and Stirrups & Hinges & $\begin{array}{c}\text { Acceptance } \\
\text { Criteria/Type }\end{array}$ \\
\hline \multirow[t]{3}{*}{ Beams } & $\begin{array}{l}\text { First and second } \\
\text { floors }\end{array}$ & & $\begin{array}{l}\text { Rectangular } \\
35 \times 35(\mathrm{~cm})\end{array}$ & $\begin{array}{c}4 \varnothing 18 \\
\varnothing 10 @ 10,20 \mathrm{~cm} \\
\text { (top \& bottom) }\end{array}$ & Flexural $\left(\mathrm{M}_{3}\right)$ & $\begin{array}{c}0.01 \mathrm{rad} \\
\text { Plastic rotation }\end{array}$ \\
\hline & $\begin{array}{l}\text { Third and fourth } \\
\text { floors }\end{array}$ & & $\begin{array}{l}\text { Rectangular } \\
35 \times 30(\mathrm{~cm})\end{array}$ & $\begin{array}{c}401608 @ 10, \\
20 \mathrm{~cm} \text { (top \& } \\
\text { bottom) }\end{array}$ & Flexural $\left(\mathrm{M}_{3}\right)$ & $\begin{array}{c}0.01 \mathrm{rad} \\
\text { Plastic rotation }\end{array}$ \\
\hline & $\begin{array}{l}\text { Fifth and sixth } \\
\text { floors }\end{array}$ & & $\begin{array}{l}\text { Rectangular } \\
35 \times 25(\mathrm{~cm})\end{array}$ & $\begin{array}{c}3 \varnothing 16 \varnothing 8 @ 10, \\
20 \mathrm{~cm} \text { (top \& } \\
\text { bottom) }\end{array}$ & Flexural $\left(\mathrm{M}_{3}\right)$ & $\begin{array}{c}0.01 \mathrm{rad} \\
\text { Plastic rotation }\end{array}$ \\
\hline \multirow[t]{3}{*}{ Columns } & $\begin{array}{l}\text { First and second } \\
\text { Floors }\end{array}$ & & $\begin{array}{l}\text { Rectangular } \\
40 \times 40(\mathrm{~cm})\end{array}$ & 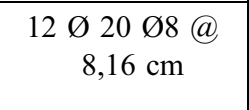 & $\begin{array}{c}\text { Flexural }+ \text { Axial } \\
\qquad\left(\mathrm{P}-\mathrm{M}_{3}\right)\end{array}$ & $\begin{array}{c}0.012 \mathrm{rad} \\
\text { Plastic rotation }\end{array}$ \\
\hline & $\begin{array}{l}\text { Third and fourth } \\
\text { floors }\end{array}$ & & $\begin{array}{l}\text { Rectangular } \\
35 \times 35(\mathrm{~cm})\end{array}$ & 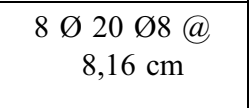 & $\begin{array}{c}\text { Flexural + Axial } \\
\qquad\left(\mathrm{P}-\mathrm{M}_{3}\right)\end{array}$ & $\begin{array}{c}0.012 \mathrm{rad} \\
\text { Plastic rotation }\end{array}$ \\
\hline & $\begin{array}{l}\text { Fifth and sixth } \\
\text { floors }\end{array}$ & & $\begin{array}{l}\text { Rectangular } \\
30 \times 30(\mathrm{~cm})\end{array}$ & $\begin{array}{c}8018 \varnothing 8 @ \\
10,20 \mathrm{~cm}\end{array}$ & $\begin{array}{c}\text { Flexural }+ \text { Axial } \\
\left(\mathrm{P}^{\left.-\mathrm{M}_{3}\right)}\right.\end{array}$ & $\begin{array}{c}0.012 \mathrm{rad} \\
\text { Plastic rotation }\end{array}$ \\
\hline \multirow[t]{4}{*}{ Braces } & $\begin{array}{l}\text { Second and third } \\
\text { floors }\end{array}$ & $\mathrm{X}$ & $\begin{array}{c}\text { Box } \\
10 \times 10 \times 0.7 \\
(\mathrm{~cm})\end{array}$ & - & Axial (P) & $\begin{array}{c}7 \Delta_{\mathrm{T}} \\
\text { Plastic deformation }\end{array}$ \\
\hline & $\begin{array}{l}\text { Fourth, fifth, \& } \\
\text { sixth floors }\end{array}$ & & $\begin{array}{c}\text { Box } 8 \times 8 \times 0.5 \\
(\mathrm{~cm})\end{array}$ & - & Axial (P) & $\begin{array}{c}7 \Delta_{\mathrm{T}} \\
\text { Plastic deformation }\end{array}$ \\
\hline & First floor & ODBS & $\begin{array}{c}\text { Components } 1 \text { and } \\
2 \text { : Box } \\
10 \times 10 \times 0.7 \\
(\mathrm{~cm})\end{array}$ & - & Axial (P) & $\begin{array}{c}7 \Delta_{\mathrm{T}} \\
\text { Plastic deformation }\end{array}$ \\
\hline & & & $\begin{array}{l}\text { Component } 3 \text { Box } \\
3 \times 3 \times 0.3(\mathrm{~cm})\end{array}$ & & & $\begin{array}{c}9 \Delta_{\mathrm{T}} \\
\text { Plastic deformation }\end{array}$ \\
\hline
\end{tabular}

Table 6 gives the obtained values of proportional deformation (drift) of two adjacent floors. The obtained drift ratio, defines the amount of displacement in each floor. The Table 6 illustrates the amount of inter-story drift for each model of second, sixth, and fifteenth stories under the defined earthquakes for types of flexural, x-braced and offdiagonal bracing systems.

Corresponding inter-story values are indicated in Fig. 18. The inter-story drifts shown in three types of flexural, $x$ brace and off-diagonal braced frame. Differences between various simulated models are compared for their behaviours under three records Naghan, Tabas and Elcentro that they are scaled previously. Figures show the ODBS braced frame has maximum inter-story drift between the base and the first floor but, in upper floors this drift is minimized higher than the other systems. According to Fig. 18 the maximum displacement of ODBS structures in the first story, demonstrate large amount of energy absorption in this system.

If the results of various types of bracing system have been considered, the maximum inter-story drift is happened in the medium height of flexural frame and $\mathrm{x}$-bracing frame wherever their fractural mode was happened there, at the same levels. Whereas in the ODBS braced frame, the maximum inter-story drift was happened in the first story and the other inter-story drifts were occurred proportional to the first story and almost decreased. This is the optimal and the ideal behaviour in a structure but, in the other systems the pattern of stiffness sorting that, it is from high to low stiffness, have not been respected and this is the reason of increasing the cost of construction, especially for structural skeleton. ODBS system has not only decrease of drift in upper story levels but also decrease of stiffness. In an approximately estimation of cost, the ODBS system has lowest cost for construction compare with the other $\mathrm{RC}$ bracing systems.

\subsection{Plastic Hinges in terms of Levels of Performance}

Subjoining the ODBS to concrete flexural frame is not only the cause of more plastic hinges formation in components of beam and column, but also the system ductility increases especially for three to ten story structures, as a result of producing axial plastic hinges of ODBS components. Considering the design of frame sections based on linear static analysis, a limited number of plastic hinges are formed in flexural frame and all of the members will not be 


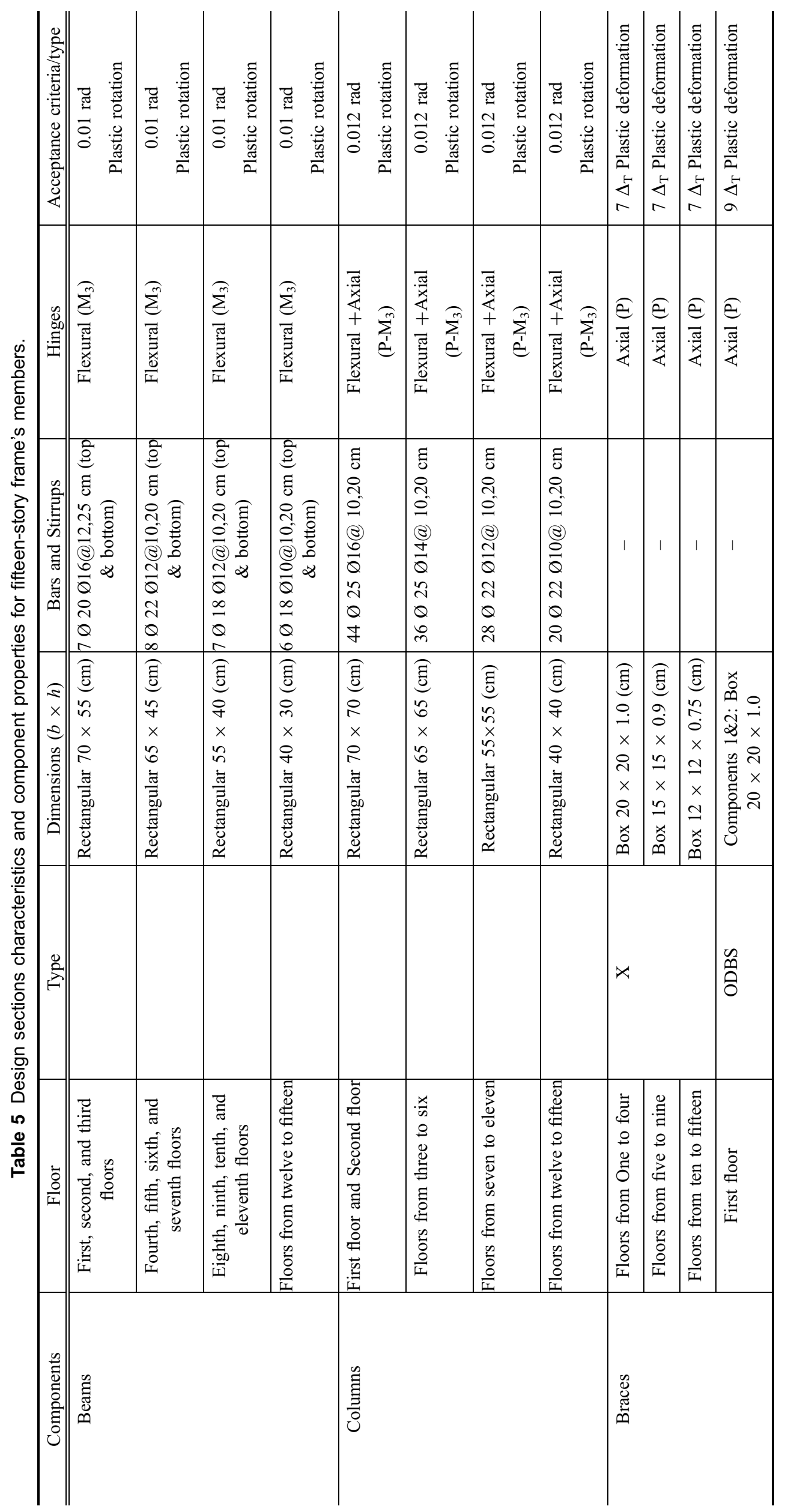



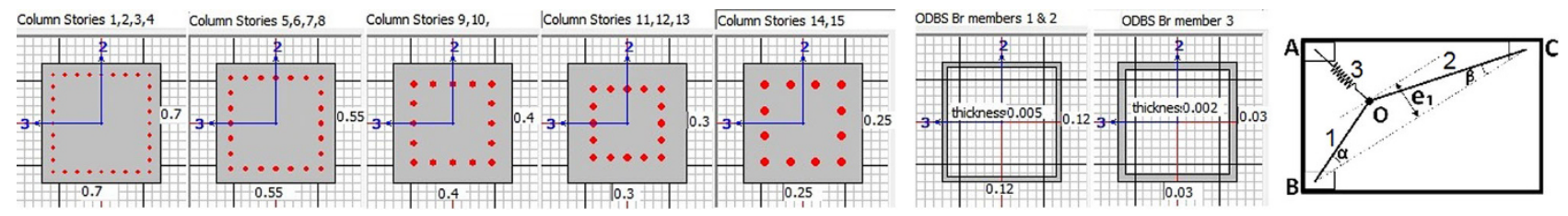

Fig. 17 Properties for applied sections used for this research models.

Table 6 Inter-story drift values for each model by second, sixth, and fifteenth stories under the earthquakes Naghan, Tabas, and Elcentro respectively (from left to right) and also in types of flexural, x-braced and off-diagonal bracing systems.

\begin{tabular}{|c|c|c|c|c|c|c|c|c|c|c|c|c|}
\hline \multicolumn{13}{|c|}{ Inter story drift for Naghan, Tabas \& Elcentro respectively $(\mathrm{cm})$} \\
\hline \multirow[t]{2}{*}{ Floor } & \multicolumn{12}{|c|}{ 2- Stories Model } \\
\hline & \multicolumn{3}{|c|}{ Flexural frame } & \multicolumn{3}{|c|}{$\mathrm{x}$-braced frame } & \multicolumn{6}{|c|}{ ODBS braced frame (all stories) ODBS braced frame (first story } \\
\hline 1 & 0.35 & 0.32 & 0.38 & 0.17 & 0.16 & 0.21 & 0.23 & 0.26 & 0.28 & 0.37 & 0.29 & 0.56 \\
\hline 2 & 0.28 & 0.21 & 0.24 & 0.11 & 0.09 & 0.12 & 0.21 & 0.18 & 0.25 & 0.17 & 0.12 & 0.21 \\
\hline Floor & \multicolumn{12}{|c|}{ 6- Stories Model } \\
\hline 1 & 2.95 & 1.68 & 2.93 & 0.62 & 0.6 & 1.4 & 1.08 & 1.67 & 2.63 & 3.28 & 2.96 & 3.95 \\
\hline 2 & 1.05 & 1.98 & 2.85 & 0.7 & 0.83 & 1.71 & 2.76 & 1.24 & 3.12 & 0.94 & 0.91 & 1.08 \\
\hline 3 & 2.48 & 1.85 & 2.33 & 0.8 & 1.15 & 1.93 & 2.05 & 2.93 & 3.34 & 0.85 & 0.63 & 0.79 \\
\hline 4 & 1.49 & 1.08 & 1.45 & 1.45 & 2.41 & 1.68 & 1.46 & 1.25 & 1.68 & 0.72 & 0.85 & 1.13 \\
\hline 5 & 1.2 & 0.9 & 1.21 & 0.72 & 1.52 & 0.79 & 0.77 & 0.72 & 0.9 & 0.43 & 0.52 & 0.54 \\
\hline 6 & 0.8 & 0.58 & 0.86 & 0.51 & 0.89 & 0.46 & 0.68 & 0.55 & 0.88 & 0.08 & 0.29 & 0.42 \\
\hline Floor & \multicolumn{12}{|c|}{ 15- Stories Model } \\
\hline 1 & 1.49 & 0.47 & 0.98 & 0.95 & 0.6 & 0.8 & 3.11 & 2.12 & 3.43 & 3.43 & 4.05 & 5.93 \\
\hline 2 & 3.13 & 0.51 & 1.83 & 0.9 & 0.45 & 0.4 & 3.66 & 3.03 & 4.21 & 4.21 & 1.03 & 1.21 \\
\hline 3 & 2.45 & 1.37 & 2.93 & 0.75 & 0.39 & 1 & 3.71 & 3.47 & 3.63 & 3.63 & 0.96 & 0.99 \\
\hline 4 & 2.17 & 1.21 & 3.91 & 1.47 & 0.51 & 1.1 & 3.43 & 3.42 & 3.36 & 3.36 & 0.89 & 0.93 \\
\hline 5 & 2.96 & 1.53 & 4.85 & 1.68 & 1.41 & 2.1 & 2.84 & 2.98 & 3.02 & 3.02 & 0.98 & 0.76 \\
\hline 6 & 3.85 & 1.92 & 3.72 & 1.93 & 1.5 & 2,6 & 1.98 & 2.18 & 2.45 & 2.45 & 0.85 & 0.85 \\
\hline 7 & 4.61 & 2.13 & 3.53 & 0.76 & 0.95 & 3.01 & 2.45 & 1.97 & 3.38 & 3.38 & 0.77 & 1.45 \\
\hline 8 & 3.42 & 1.94 & 2.98 & 0.93 & 2.1 & 1.76 & 3.53 & 2.63 & 3.23 & 3.23 & 0.63 & 1.23 \\
\hline 9 & 3.23 & 2.73 & 2.45 & 0.81 & 2.05 & 2.51 & 2.81 & 2.51 & 3.87 & 3.87 & 1.51 & 0.82 \\
\hline 10 & 3.12 & 2.92 & 2.95 & 0.75 & 2.5 & 1.12 & 1.71 & 1.33 & 2.67 & 2.67 & 1.84 & 0.79 \\
\hline 11 & 2.31 & 3.43 & 1.95 & 0.6 & 1.63 & 0.93 & 1.58 & 1.04 & 2.32 & 2.32 & 1.51 & 0.71 \\
\hline 12 & 1.86 & 2.95 & 1.43 & 0.72 & 0.95 & 0.81 & 1.62 & 0.73 & 2.13 & 2.13 & 1.06 & 0.62 \\
\hline 13 & 1.03 & 2.08 & 1.32 & 0.58 & 0.71 & 0.6 & 1.08 & 0.66 & 1.48 & 1.48 & 0.43 & 0.51 \\
\hline 14 & 0.68 & 1.81 & 1.11 & 0.49 & 0.45 & 0.48 & 0.78 & 0.51 & 0.94 & 0.94 & 0.41 & 0.43 \\
\hline 15 & 0.34 & 0.71 & 0.95 & 0.33 & 0.2 & 0.23 & 0.54 & 0.36 & 0.67 & 0.67 & 0.32 & 0.36 \\
\hline
\end{tabular}

able to produce plastic hinges, but when the steel off-diagonal bracing system is added to flexural frame, increasing the rotational capacity of RC members and also increasing the number of composed plastic hinge are some indices of increased ductility of ODBS braced RC flexural frame. Many results are generated along this analysis in ODBS braced RC frame before any damages, the third member of this system has been rotated and deflected near the plastic limit. In this hand, the initial sever vibrations have been damped through the flexibility of ODBS system and also its members elongation and energy absorption. Figure 19 illustrates the formation of plastic hinges and their rotational capacity.

Generated plastic hinges is indicated in Fig. 19. As shown in this figure, the off-diagonal system has the highest level of deformation not only in RC frame members but also in steel 


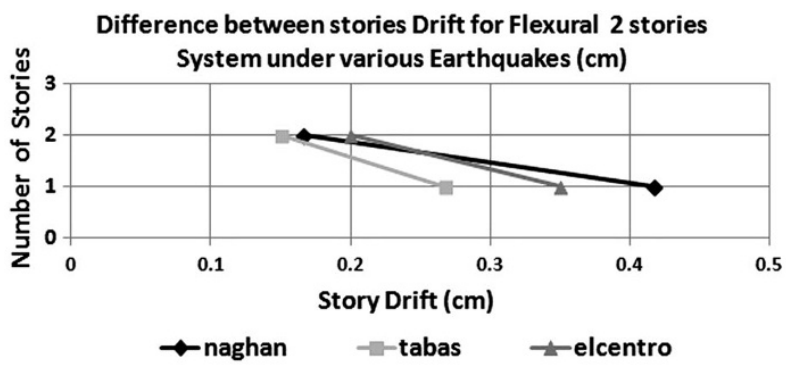

(a) $2^{\text {st }}$ Flexural Frame

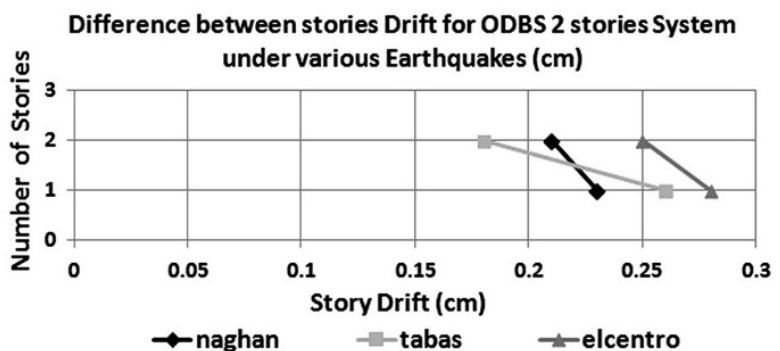

(c) $2^{\text {st }}$ ODBS braced frame (all stories)

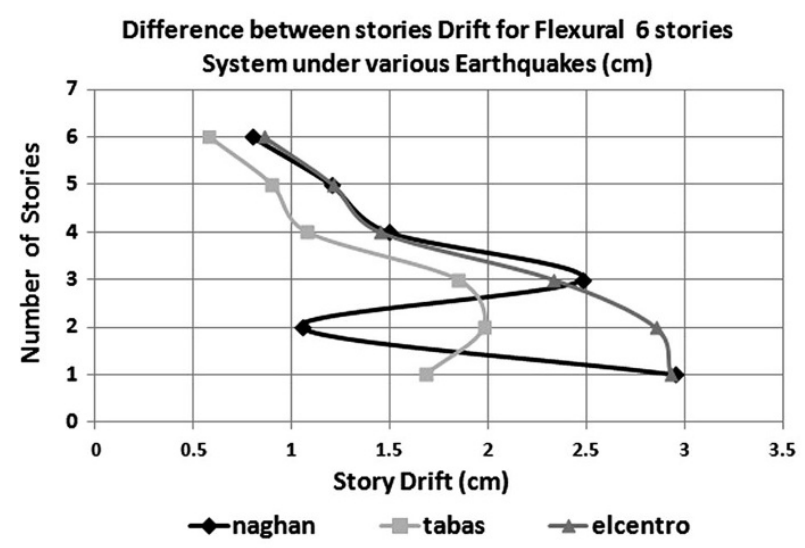

(a) $6^{\text {st }}$ Flexural Frame

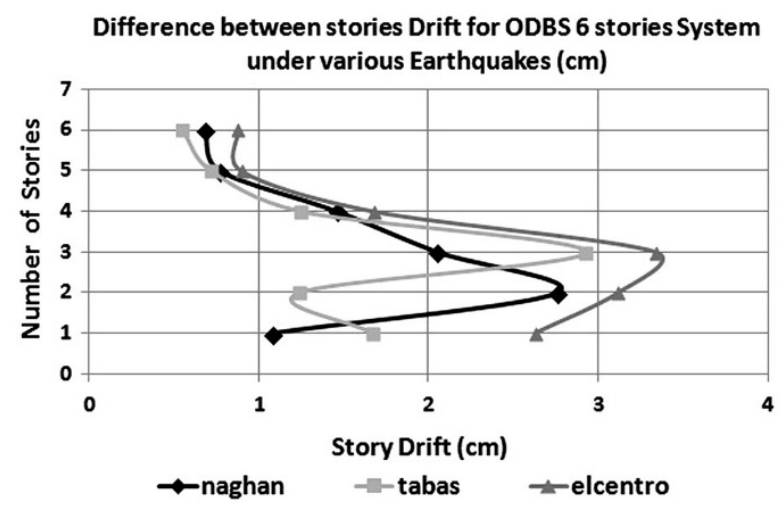

(c) $6^{\text {st }}$ ODBS braced frame (all stories)

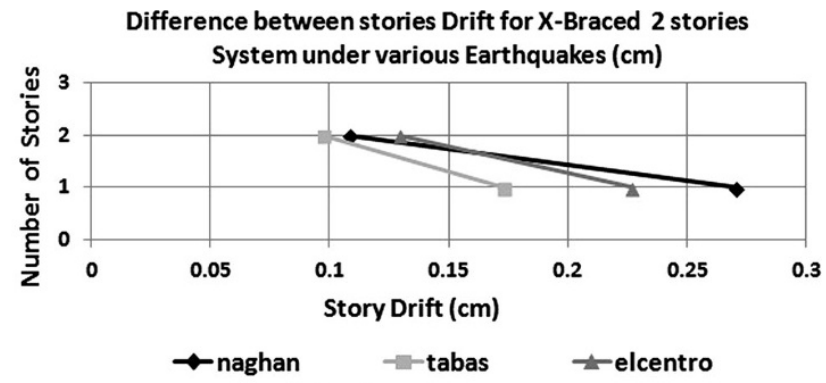

(b) $2^{\text {st }} \mathrm{X}$-Braced Frame

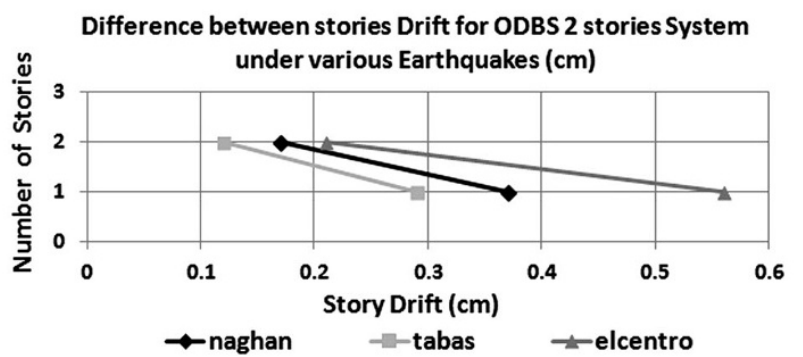

(d) $2^{\text {st }}$ ODBS braced frame (first story)

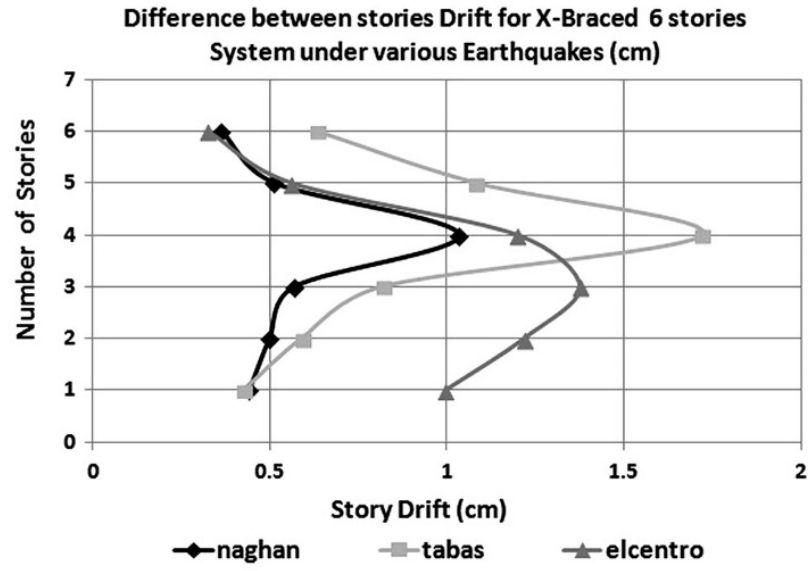

(b) $6^{\text {st }} \mathrm{X}$-Braced Frame

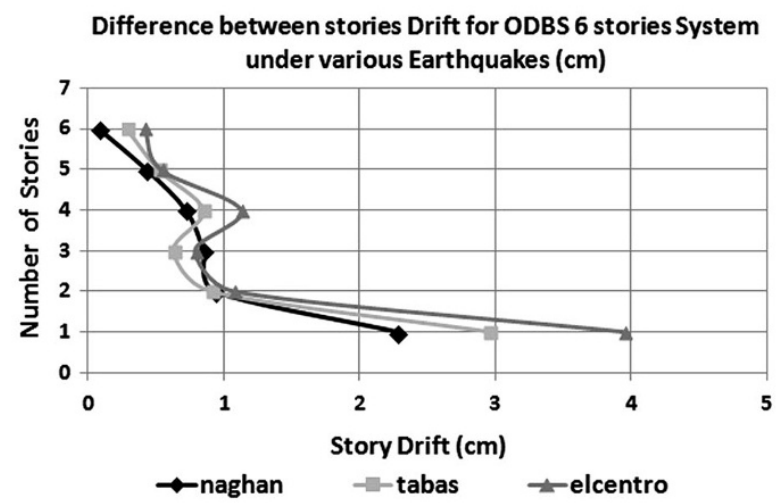

(d) $6^{\text {st }}$ ODBS braced frame (first story)

Fig. 18 Variation of inter-story drifts $(\mathrm{cm})$ under various earthquakes by three types of 2, 6 and 15 stories frame respectively for a flexural frame, b x-braced, c ODBS system used in all stories and d ODBS system used only in the first story.

members, especially in third member of steel ODBS. The rotational capacity is increased in ODBS, the most ductile system. Performance levels of flexural and X-braced frames are limited to Life Safety (LS) level, but for ODBS, level of performance has been extended to higher ductility about related design criteria. Six and fifteen stories flexural frames have plastic hinges more than X-braced frame. On the other hand in ODBS, more members are contributed in absorption of defined existing energy by nonlinear ductile behavior of plastic rotation and deformation proportional to flexural 
frame. Non-linear static analyses as well as dynamic step by step seismic analyses are performed and special purpose elements are employed for the needs of this study. Results showing the influence of the maximum rotation of the multistorey frame members in terms of ductility requirements and rotational requirements of the frame members (Karayannis et al.).

Difference between stories Drift for Flexural 15 stories System under various Earthquakes (cm)

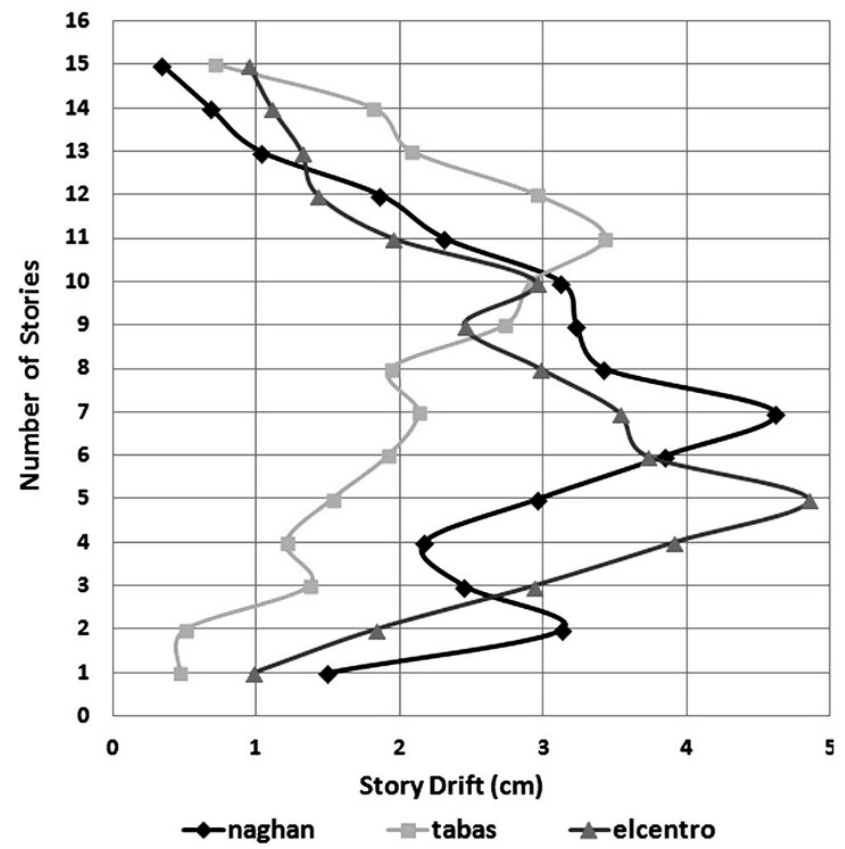

(a) $15^{\text {st }}$ Flexural Frame

Difference between stories Drift for ODBS 15 stories System under various Earthquakes $(\mathrm{cm})$

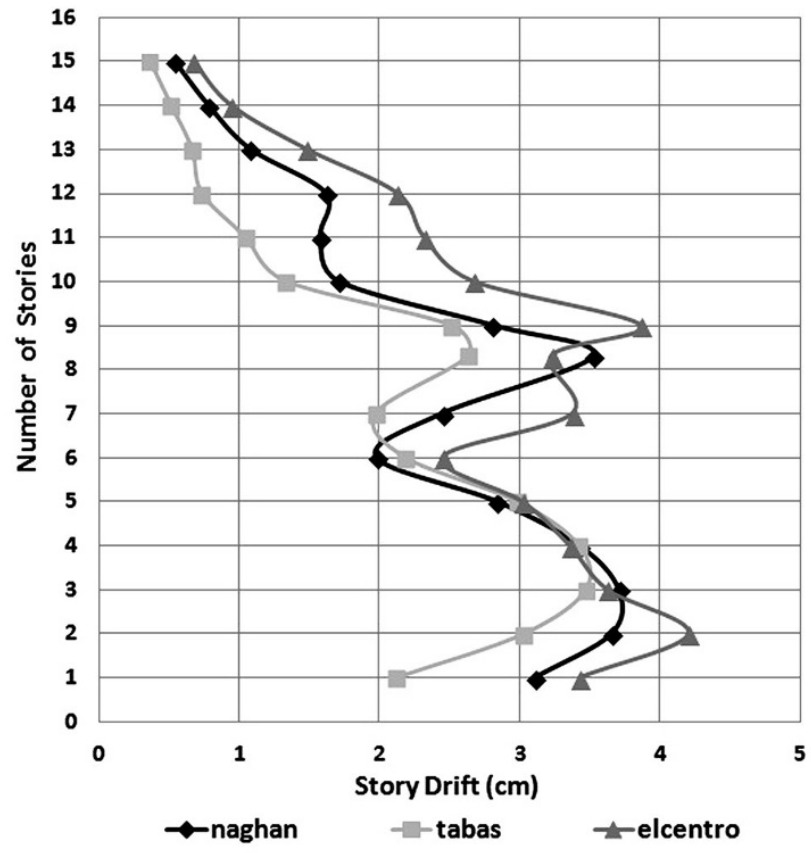

(c) $15^{\text {st }}$ ODBS braced frame (all stories)
Acceptance criteria for flexural frame of LS level is 0.02 for primary components and also the acceptance criteria for ODBS braced frame of CP level is 0.025 and 0.05 for primary and secondary components respectively. A more detailed scrutinizing of the results reveals that the hinges formed in ODBS system endure the maximum deformation and earn the structure a very high performance level along

Difference between stories Drift for X-Braced 15 stories System under various Earthquakes $(\mathrm{cm})$

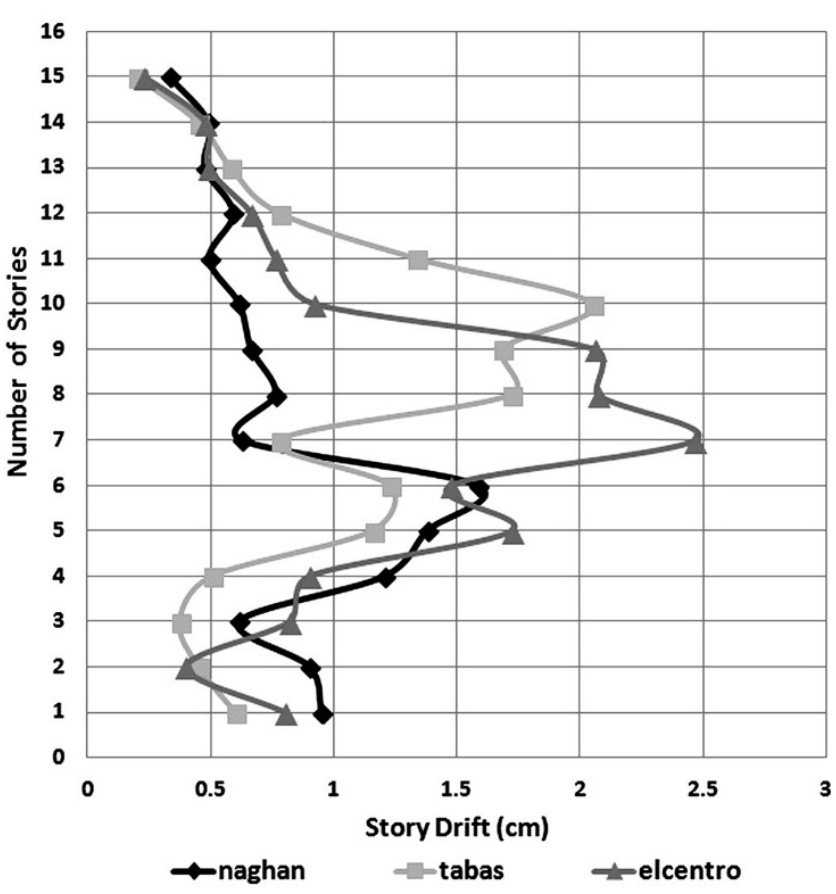

(b) $15^{\text {st }}$ X-Braced Frame

Difference between stories Drift for ODBS 15 stories System under various Earthquakes $(\mathrm{cm})$

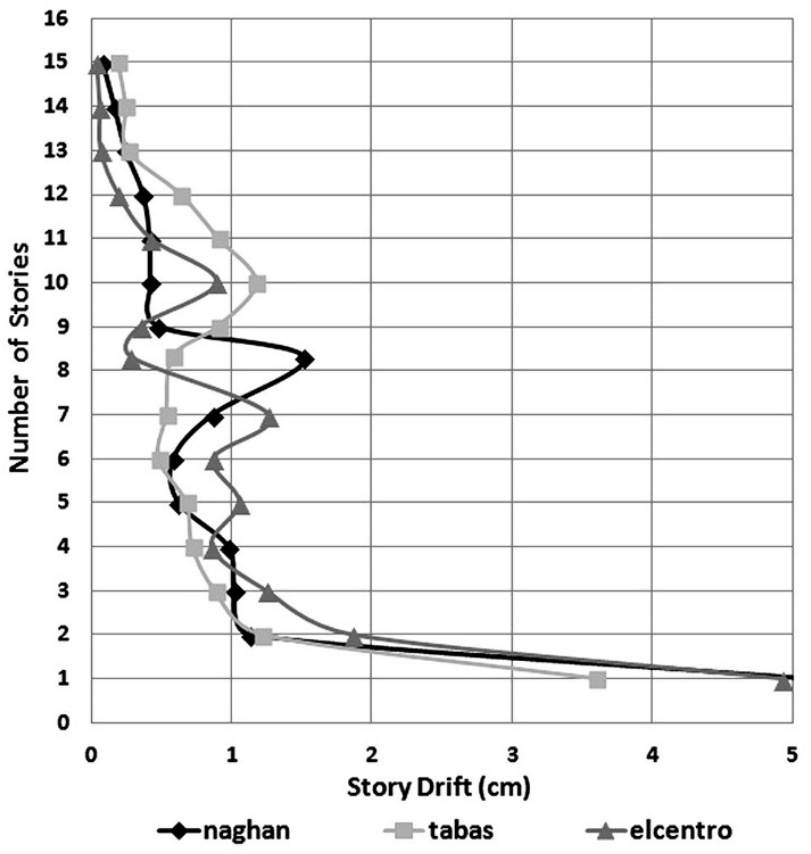

(d) $15^{\text {st }}$ ODBS braced frame (first story)

Fig. 18 continued 


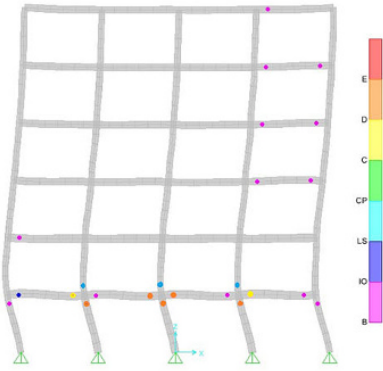

(a) Flexural Frame

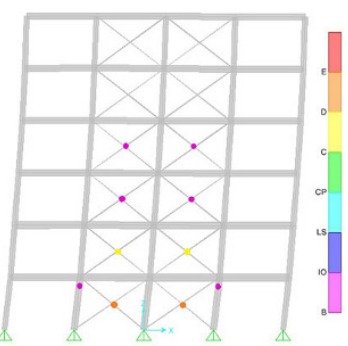

(b) X-Braced Frame

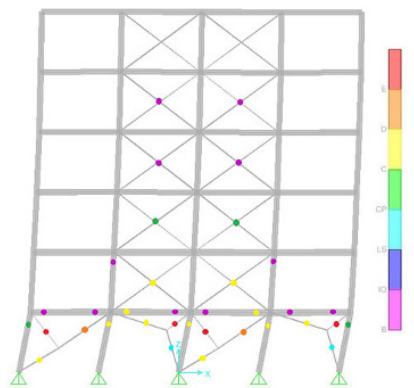

(c) ODBS Braced Frame

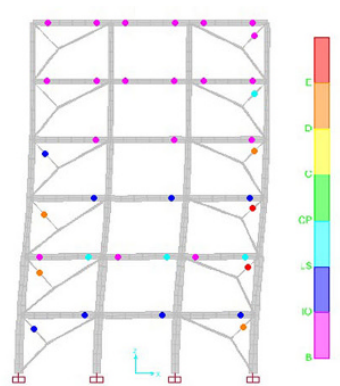

(d) all stories ODBS

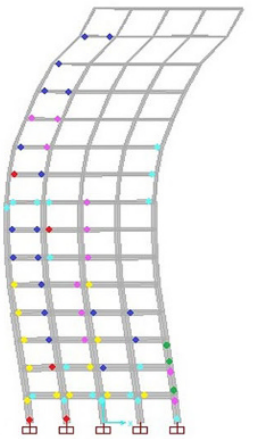

(a) Flexural Frame

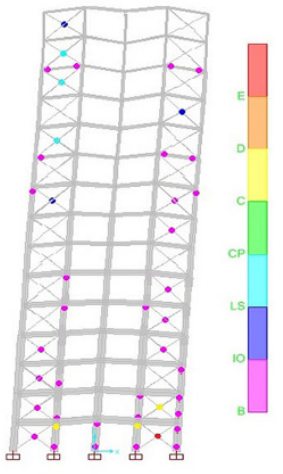

(b) X-Braced Frame

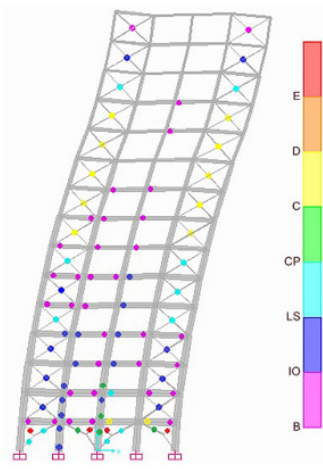

(c) ODBS Braced Frame

Fig. 19 Sequence of performed plastic hinges under Tabas ground motion by considering geometric nonlinearity for six \& fifteen stories RC frames, a flexural frames, $\mathbf{b}$ x-braced frames, $\mathbf{c}$ ODBS braced frames consisting and $\mathbf{d}$ all stories ODBS braced frame.

Table 7 The values of maximum response of ODBS braced frame under various eccentricities.

\begin{tabular}{c|c|c|c|c|c|c|c}
\hline \multicolumn{5}{|c|}{ Elcentro time-history acceleration response } & \multicolumn{4}{c}{ General characteristics } \\
\hline Models \& index & Max. Ecc $\left(\mathrm{e}_{1}\right)$ & Max. Acc $(\mathrm{g})$ & Max.Vel $(\mathrm{cm} / \mathrm{s})$ & Max. Displ (cm) & $\begin{array}{c}\text { Initial stiffness } \\
(\mathrm{kN} / \mathrm{cm})\end{array}$ & $\begin{array}{c}\text { Period }(1 \mathrm{st} \\
\text { mode) }(\mathrm{s})\end{array}$ & $\begin{array}{c}\Delta \text { at first yield } \\
\text { point }(\mathrm{cm})\end{array}$ \\
\hline \hline ODBS (p0) & 0.00 & 0.342 & 46.08 & 3.93 & 491.78 & 0.47 & 2.83 \\
\hline ODBS (p1) & 0.1 & 0.261 & 40.14 & 4.67 & 315.59 & 0.59 & 2.49 \\
\hline ODBS (p2) & 0.2 & 0.175 & 37.72 & 5.10 & 158.51 & 0.83 & 2.31 \\
\hline ODBS (p3) & 0.3 & 0.073 & 33.3 & 6.06 & 77.49 & 1.19 & 2.1 \\
\hline ODBS (p4) & 0.4 & 0.034 & 34.71 & 6.81 & 37.77 & 1.71 & 1.7 \\
\hline ODBS (p5) & 0.5 & 0.028 & 36.95 & 6.22 & 17.36 & 2.52 & 1.6 \\
\hline ODBS (p6) & 0.6 & 0.023 & 38.71 & 6.16 & 6.50 & 4.12 & 1.3 \\
\hline ODBS (p7) & 0.7 & 0.018 & 40.08 & 6.00 & 1.23 & 9.48 & 1.1 \\
\hline X-Bracing & - & 0.581 & 78.35 & 2.04 & 894.39 & 0.39 & 2.96 \\
\hline
\end{tabular}

ductile behavior. In addition, the more performance levels of plastic hinges are gathered in the structure, so by this level of ductility, the structure will be absorbed more quantity of energy. These results are deduced based on non-linear dynamic step by step analyses. The time steps for this analysis is considered less than $\Delta \mathrm{T}=0.02 \mathrm{~s}$. Future research will be dedicated to the full time history analysis and investigate the proportional hysteresis curves. Assessing the stiffness and/or the strength degrading is the most important to diagnosing the exact behavior of this system.
According to Fema-356 (FEMA-356 2000, Table 6-7 and Table 6-8), the plastic rotation of mentioned beams and columns of flexural frame are 0.025 and 0.02 rad respectively. These quantities are $0.05,0.03 \mathrm{rad}$ in the system like ODBS by high ductility and therefore, the structural damage can be prevented to a great extent. This is why the structure's ductility and its capacity of energy absorption decreases considerably when the structural performance is limited to the formation of first crack. As it is obvious, when the hinges occur in the beam and columns' concrete elements, the drift 

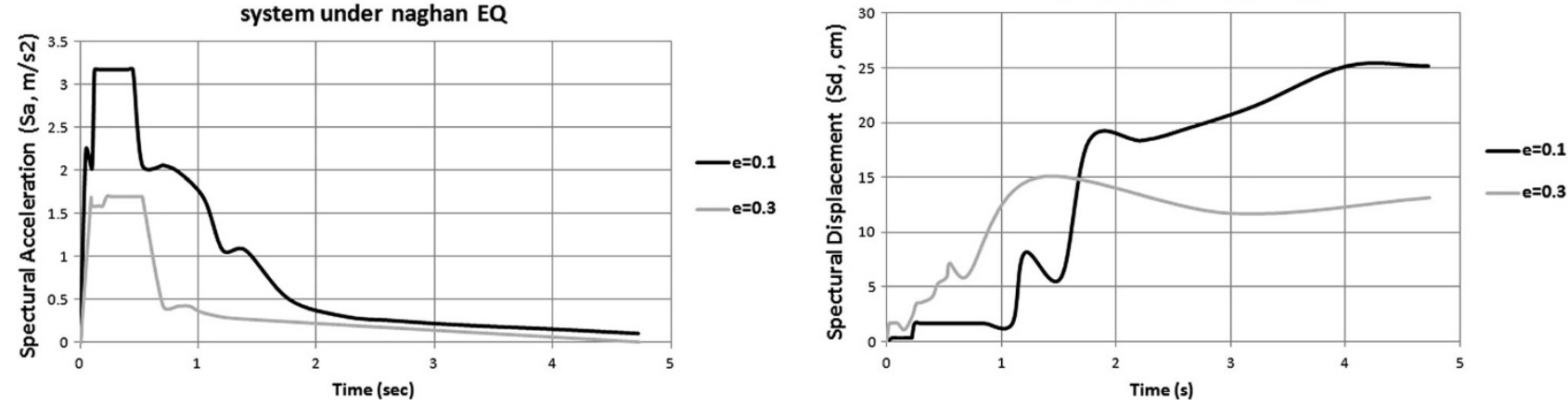

Fig. 20 Comparison response of ODBS system along Naghan earthquake for different eccentricities, spectral acceleration (left) and spectral displacement (right).
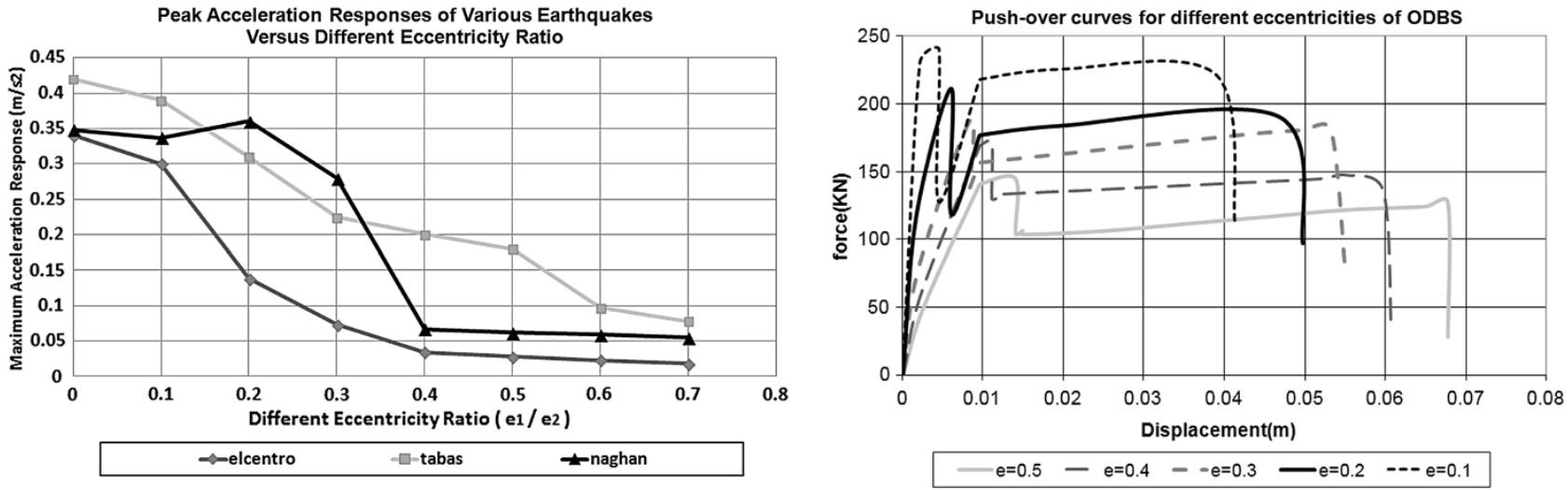

Fig. 21 Maximum Acceleration versus eccentricity ratio under Elcentro, Tabas and Naghan earthquakes (a), Ductility assessment of various eccentricities corresponding to pushover curves comparison (b).

and rotation of the frame attain to $\mathrm{C}$ and $\mathrm{D}$ points in the ODBS pushover curve, which will satisfy the safety requirements versus any deterioration related to its hazard and risk level. Thus, it is concluded that the application of steel ODBS in concrete flexural frame is quite suitable and earns the structural outstanding characteristics from the viewpoint of the economy and ductility of reinforced concrete frame.

\subsection{Effects of Eccentricity on ODBS System}

In other investigation, to recognize the effects of eccentricity on the seismic behaviour and the spectral response of ODBS, a six-story frame by previous properties is performed under spectral analysis. To this modeling, various eccentricities are considered from $\mathrm{e}=0.0$ to $\mathrm{e}=0.7$ and also the response of spectral acceleration, velocity and displacement is investigated for a base point on the upper level of sixth story floor. The ODBS system along primary spectral analysis is investigated under effect of Naghan earthquake and the related results are obtained as Fig. 20. Spectral acceleration quantities are registered for two different eccentricities $\mathrm{e}=0.1$ and $\mathrm{e}=0.3$. Figure 20 (left) indicates that the result of ODBS by more eccentricity ( $\mathrm{e}=0.3$ ) was lower than the other one. As regards that the time domain of vibration for Naghan earthquake (measured period $5 \mathrm{~s}$ ), by increasing the eccentricity, the response of ODBS is decreased in a short time. Also the oscillation's intensity is decreased saliently. According to right figure, the amount of spectral displacements is indicated for ODBS by the same eccentricity. The spectral displacement for eccentricity about 0.3 was lower than the same by 0.1 for its eccentricity as indicated in right side of Fig. 20. The initial velocity for model by higher eccentricity is greater than the other model by lower eccentricity.

By investigating the recent results, it seems that the energy dissipation is increased by increasing eccentricity and indicates the optimum amount of eccentricity is about $0.1-0.4$ for ODBS systems. The eccentricities out of the range of $0.1-0.4$ are not suggested to use in structures. Table 7 includes the recorded spectral response as acceleration, velocity and spectral displacement for ODBS system by various eccentricities. By continuing the assessments, the spectral analysis is performed on x-braced frame too. The spectral response of ODBS in compare with $\mathrm{x}$-braced frame indicated the advantage of ODBS system. The stiffness and displacement characteristics of models under Elcentro earthquake are illustrated in Table 7. The intense velocity of $\mathrm{x}$-brace model proportional to ODBS is generated imposing loads by impulsive tendency within the time domain of acceleration. This phenomenon may be the cause of structural concrete deteriorations. The minimum amount of spectral velocity is concerned about ODBS braced frame by 

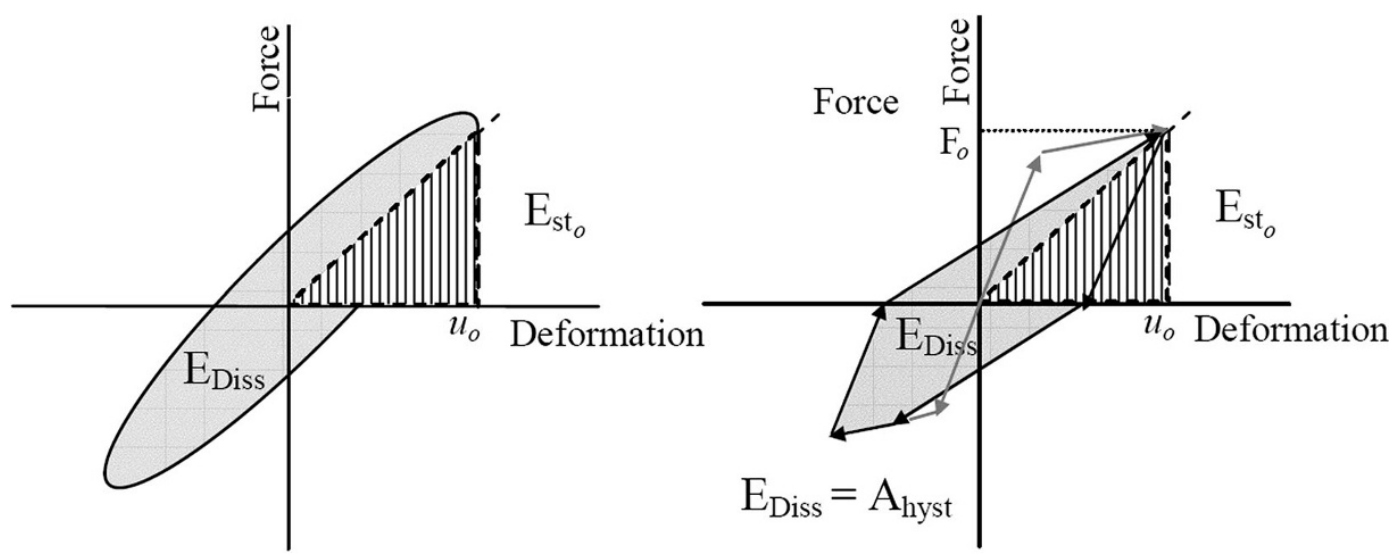

Fig. 22 Comparison between dissipated energy and stored energy for investigate viscous damping and hysteresis model.

eccentricity equal to 0.3 . The lowest amount of spectral displacement in concerned about x-braced frame and ODBS braced frame, respectively. Finally the lowest response acceleration is recorded through 0.7 for eccentricity in ODBS braced frame.

Also the dynamic behaviour of the 6-story frames, retrofitted by Off-Diagonal bracing system, under three records of Tabas, Naghan and Elcentro, has been compared for optimizing normalized eccentricity ratio. Overall result related to several eccentricities is shown in Fig. 21.

The optimum levels for displacement and acceleration is affected from the structural stiffness and the mass inertia respectively. Manual limits should be considered for minimum displacement and allowable rotation. By knowing the optimum eccentricity about $0.2-0.5$, the optimum behaviour of ODBS is generated. The relation between maximum acceleration response of ODBS and eccentricities variations under mentioned earthquake is specified as Fig. 21 (left). The results are converged for eccentricity about $0.1-0.3$ under every excitation. Pushover curve due to different eccentricities is shown in Fig. 21 (right). Results are explained as how much the ductility levels are increased.

Approximation of the equivalent viscous damping ratio is effective parameters to verify the dynamic behaviour and is considered to predict the structural damping treatment and its energy dissipation capacity. The dynamic characteristic for comparison the various load bearing systems is proportional to equivalent damping and effective stiffness. Possibility to solving a simple linear braced frame instead of nonlinear ODBS braced frame is the reason why the equivalent viscous damping is estimated considering both elastic and inelastic energy dissipation.

The previous methods to approximate the equivalent viscous damping for present structure that this system is the composed structural material has indicated just for some hysteretic models, deformability or ductility range and frequency. Time history analysis carried out correspondent some results by amount of difference in present research from exact equivalent viscous damping. The exact and effective equivalent viscous damping ratio is related about two dependent factors, ductility and frequency (or period), because of this estimated values of equivalent viscous damping ratio has been changed along any hysteresis analysis. Then the average equivalent viscous damping should be considered to investigate the present research subject.

The average value has minimum variation compare with exact value. This means that it is not an essential object to have the exact evaluation for damping ratio.

\section{Equivalent Viscous Damping}

Estimation of the equivalent viscous damping ratio is the one of effective parameters to verifying the dynamic behaviour and is considered to predict the structural damping treatment and its energy dissipation capacity. The dynamic characteristic for comparison the various load bearing systems is proportional to equivalent damping and effective stiffness. Possibility to calculating a simple linear braced frame instead of nonlinear ODBS braced frame is the reason why the equivalent viscous damping is estimated considering both elastic and inelastic energy dissipation.

By considering the unique ODBS braced RC flexural frame like a system of single degree of freedom (SDOF) and taking a part equivalent viscous damping ratio in elastic level of general damping and hysteresis damping in term of nonlinear behaviour along hysteresis analysis can be find:

$$
\xi_{\text {eq }}=\xi_{\text {lin }}+\xi_{\text {nonlin }}=\xi_{\text {elst }}+\xi_{\text {hyst }}
$$

That $\xi_{\text {elst }}$ is linear or primary damping in elastic level and $\xi_{\text {hyst }}$ is the nonlinear or secondary damping in inelastic level used for effect of energy dissipated loops. To calculate these quantities, the model should be subjected under harmonic cyclic loading by constant period in each cycle. Elastic damping ratio is assumed $5 \%$ in this study. Because of this part of Eq. (7) is outside of this research's aim and scope, this quantity is considered in constant form (assumption is based on laboratory conditions in recent researches).

Equivalent viscous damping is related to hysteretic response that they have been referred to dissipated energy $\mathrm{E}_{\text {dissip }}$ and stored energy $\mathrm{E}_{\text {stord. }}$ By parallel use of Fig. 22 and Eq. (8), the quantity of equivalent damping ratio achieved from the value of excitation frequencies in each type of natural and main harmonic excitation. 
(a)

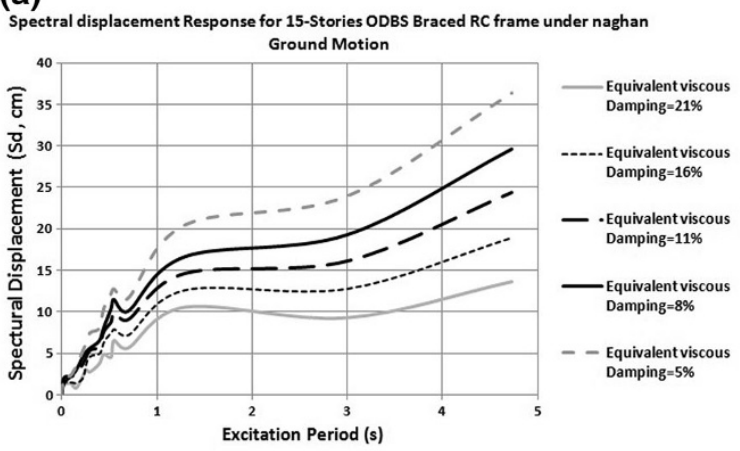

(c)

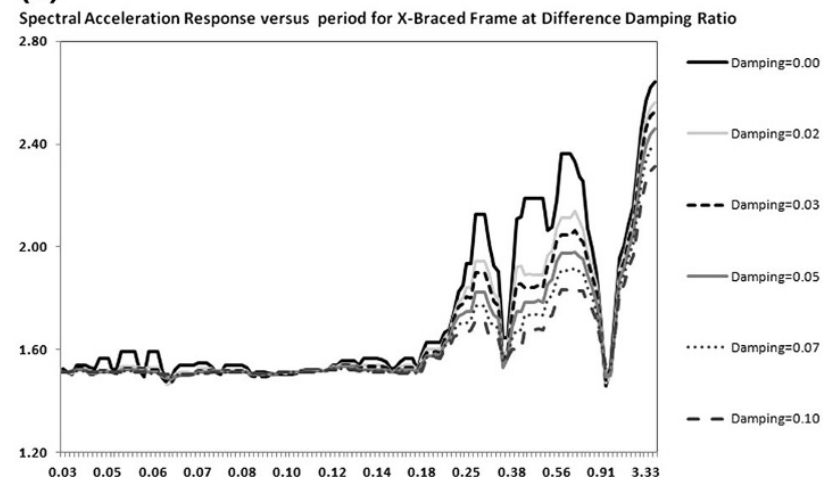

(b)

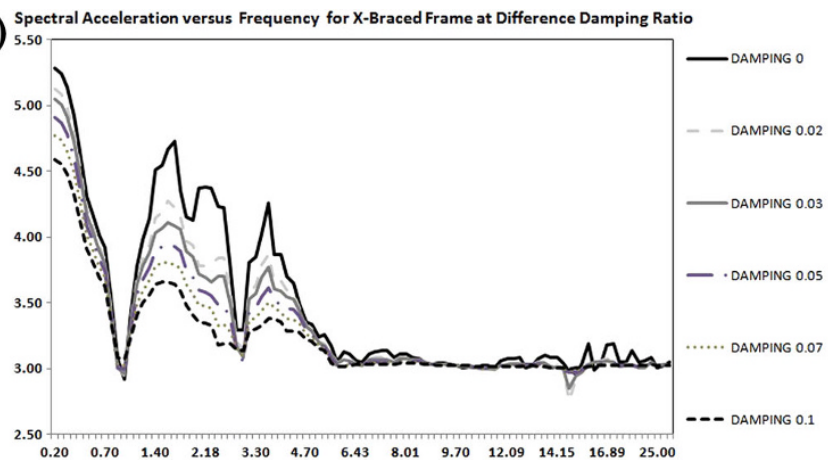

(d)

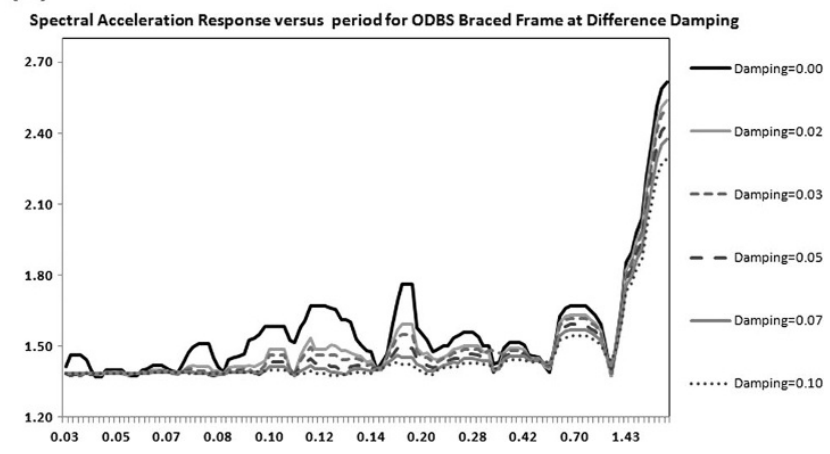

Fig. 23 Comparison spectral displacement response of ODBS frame model under Naghan excitation for different equivalent viscous damping ratios, a ODBS spectral displacement versus period, $\mathbf{b}$ flexural frame spectral acceleration versus frequency, $\mathbf{c}$ X-braced spectral acceleration versus period and $\mathbf{d}$ ODBS spectral acceleration versus period.

$$
\xi_{\text {hyst }}=\left(\frac{1}{4 \pi}\right)\left(\frac{\bar{\omega}_{n}}{\bar{\omega}}\right)\left(\frac{E_{\text {dissip }}}{E_{\text {stord }}}\right)
$$

Also the equation of motion is assumed as below:

$$
m \ddot{u}+c \dot{u}+k u=P_{0} \sin \bar{\omega} t
$$

The equation of motion in term of amplitude or maximum displacement by a phase angel along harmonic function is performed as:

$$
u(t)=u_{0} \sin (\bar{\omega} t-\varphi)
$$

The phase angel in term of natural frequency and excitation frequency and almost the damping ratio is obtained from:

$$
\varphi=\tan ^{-1} \frac{2 \xi\left(\bar{\omega} / \bar{\omega}_{n}\right)}{1-\left(\bar{\omega} / \bar{\omega}_{n}\right)^{2}}
$$

Since the energy stored calculated by:

$$
E_{\text {stord }}=\frac{k u_{0}^{2}}{2}
$$

The energy dissipation for the common motion in structure in considered as below. Substituting the functional parameter is related to each boundary condition and is performed distinguishably for any problems.

$$
E_{\text {dissip }}=\int f_{\text {damp }} \cdot d u=\int_{0}^{\frac{2 \pi}{\pi}}(C \dot{u}) \dot{u} \cdot d t
$$

This equation is defined by energy dissipated product by energy stored corresponding to characteristics of loading and time domain for imposed seismic or cyclic load. For example Eq. (8) is the one status of harmonic load substituted by $u$ and $\dot{u}$ from Eq. (13).

Also the simple relation due to previous equations the equivalent period is substituted by equivalent damping ratio in form of Eq. (14). This equation explains the greater equivalent period for ductile systems and also the greater period is the result of the greater equivalent viscous damping ratio.

$$
\frac{T_{e q}}{T}=1+0.121(\mu-1)^{0.939}
$$

In general form, another equation is proposed by Priestley (2003) corresponding to equivalent viscous damping $\left(\xi_{\text {eq }}\right)$, initial viscous damping $\left(\xi_{0}\right)$ and the ductility level of the structures $(\mu)$.

$$
\xi_{e q}=\xi_{0}+\alpha\left(1-\frac{1}{\mu^{\beta}}\right)
$$

$\alpha$ and $\beta$ constants are about the fatness and geometric property of hysteretic loops. These parameters assumption 

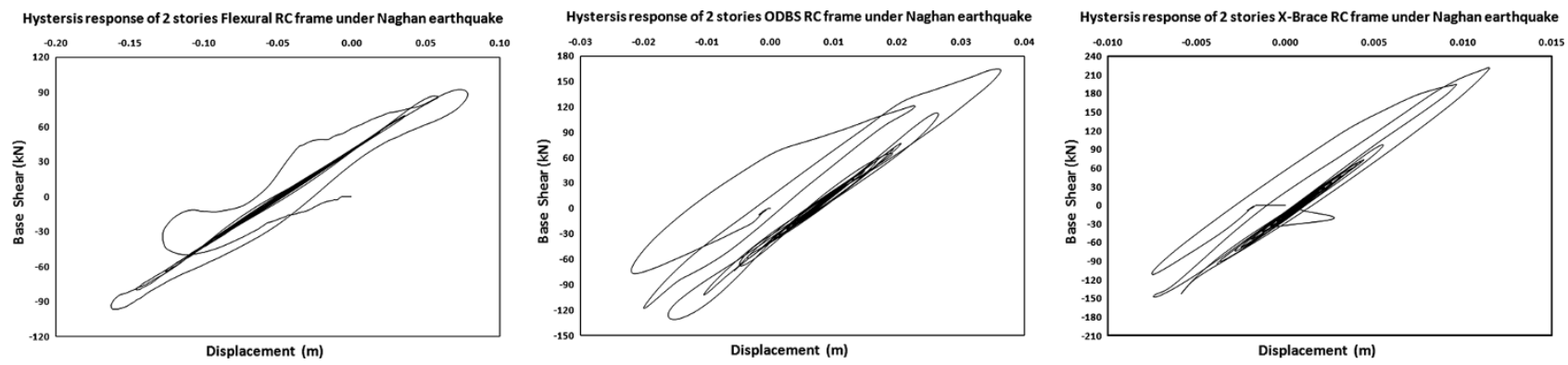

Fig. 24 Hysteretic response along Naghan seismic excitation for 2-stories Flexural frame (left), ODBS braced frame (medium) and X-braced frame $($ right).
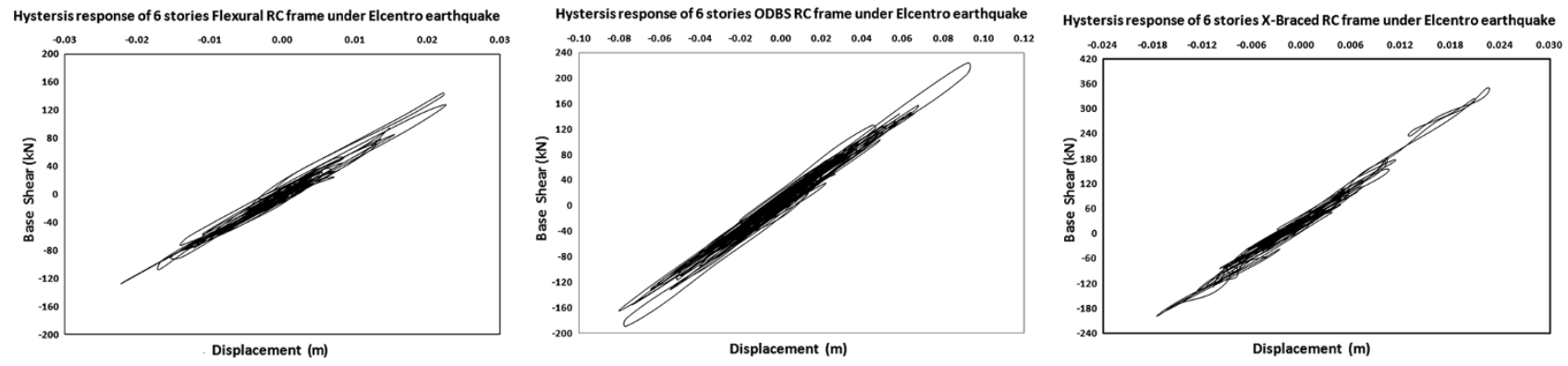

Fig. 25 Hysteretic response along Elcentro seismic excitation for 6-stories Flexural frame (left), ODBS braced frame (medium) and X-braced frame $(r i g h t)$.
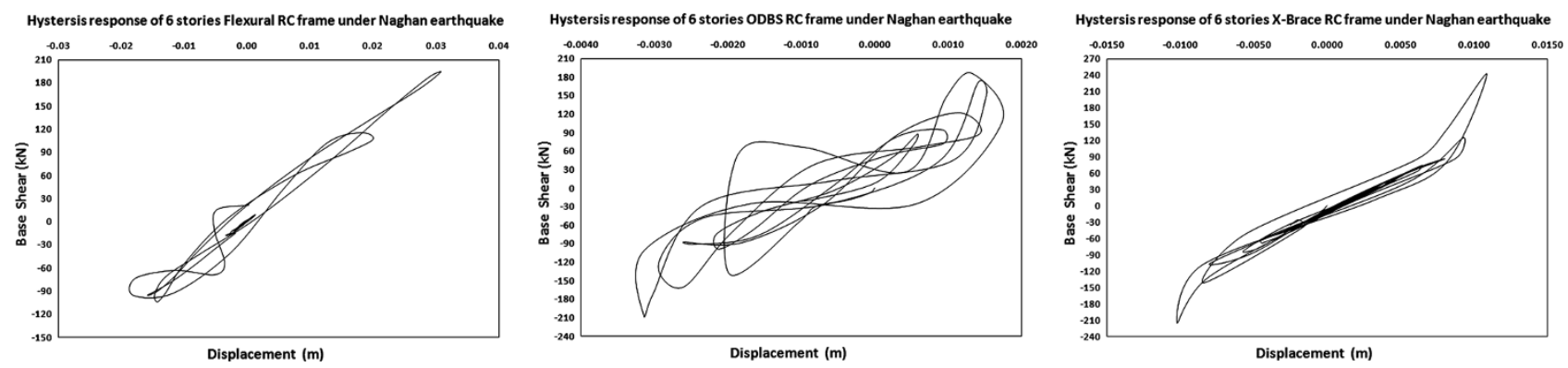

Fig. 26 Hysteretic response along Naghan seismic excitation for 6-stories Flexural frame (left), ODBS braced frame (medium) and X-braced frame $(r i g h t)$.
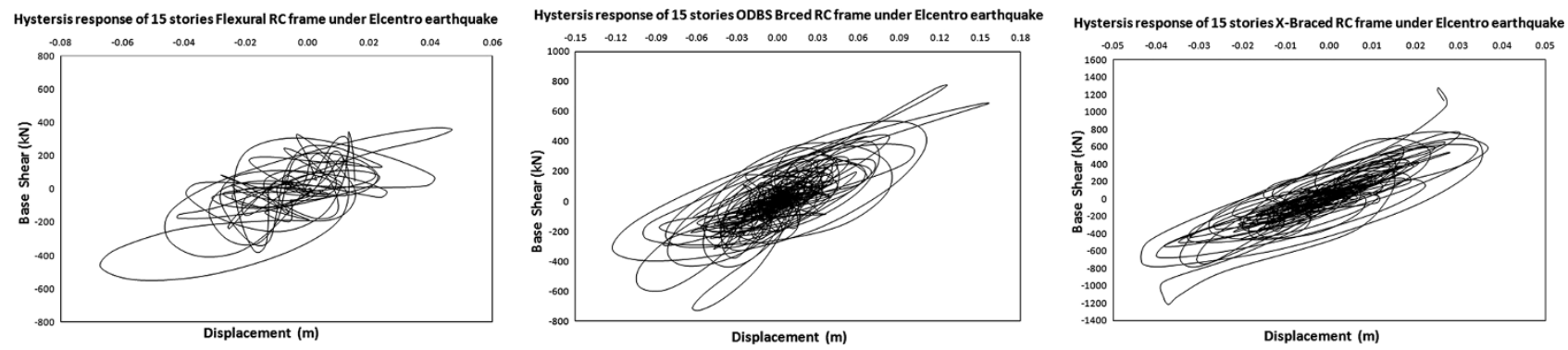

Fig. 27 Hysteretic response along Elcentro seismic excitation for 15-stories Flexural frame (left), ODBS braced frame (medium) and X-braced frame (right).

are considered by various types of selecting. Whatever seems important is increasing the equivalent viscous damping along increasing the ductility level. By consideration the $\alpha$ and $\beta$ in the fix range, the ODBS system proportional to $\mathrm{x}$-braced frame even to flexural frame, has more ductility and more equivalent viscous damping ratio too. Although the equivalent damping ratio is considered to estimate the spectral displacement response for 15 stories ODBS braced frame as shown in Fig. 23. The under consideration model has 0.25 eccentricity that is the optimized quantity to ODBS investigation. 

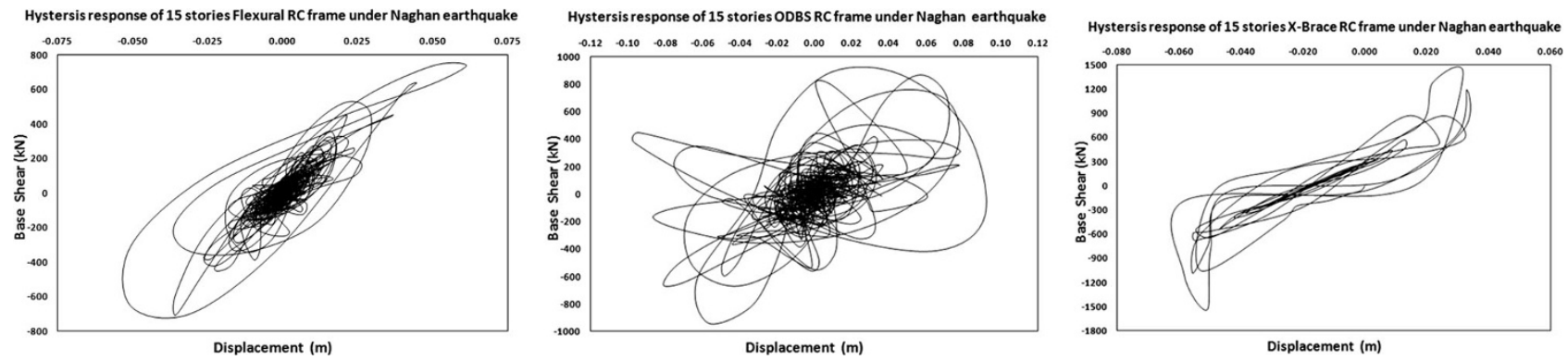

Fig. 28 Hysteretic response along Naghan seismic excitation for 15-stories Flexural frame (left), ODBS braced frame (medium) and X-braced frame (right).
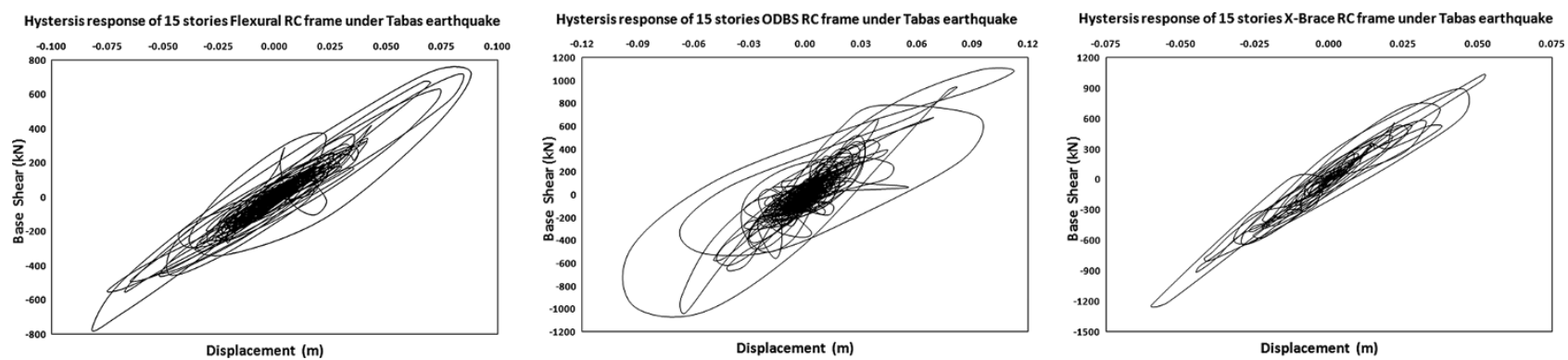

Fig. 29 Hysteretic response along Tabas seismic excitation for 15-stories Flexural frame (left), ODBS braced frame (medium) and X-braced frame $($ right).

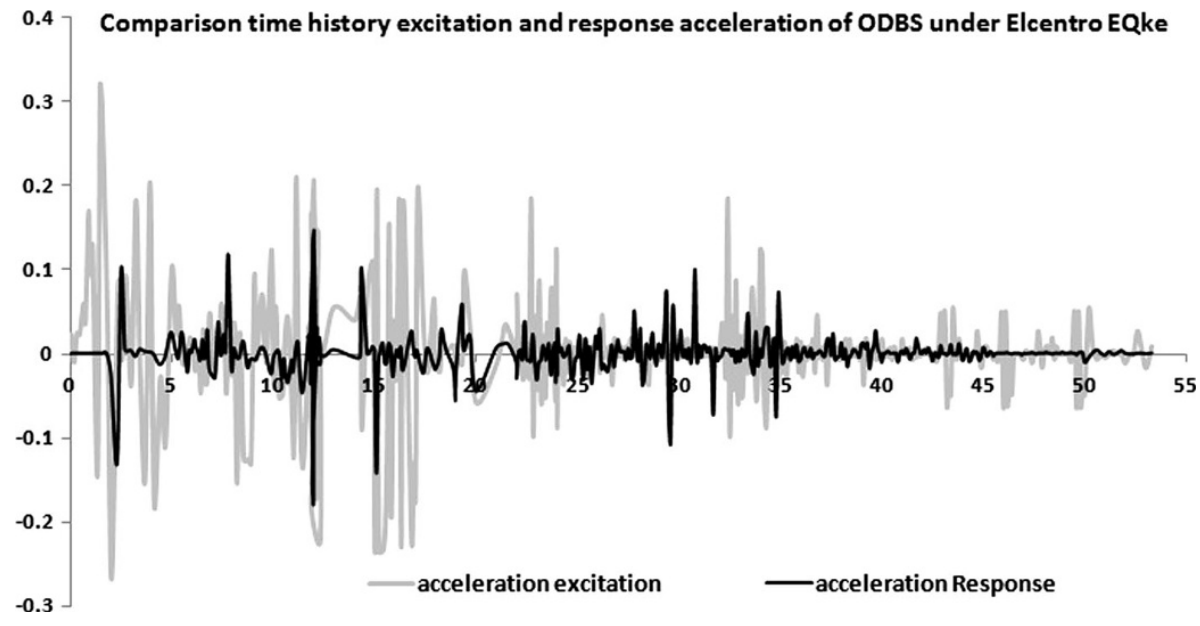

Fig. 30 Excitation of base level and ODBS response at first floor's level comparison for their accelerations under Elcentro time history.

As investigated for ODBS spectral response in last pages, the next assessment was about obtaining the equivalent viscous damping for ODBS braced frame. The obtained results according to Fig. 23 is illustrated the viscous damping characteristics for ODBS braced frame under Naghan earthquake. As indicated in recent figures and illustrative equations, the viscous damping ratio and the spectral displacements are related inversely. It means decreasing the spectral displacement is because of increasing the viscous damping for a system. In Fig. 23, the various amount of equivalent viscous damping is compared each model of ODBS and $\mathrm{x}$-braced frame together. The effects of ODBS equivalent viscous damping ratios variations were more than other systems. In Fig. 23a, c and $\mathrm{d}$, the response spectral displacements versus time periods are specified for various accelerograms assessment.

Figure 23 indicates the sequence of inelastic damping ratio for dissipating energy proportional to its exact treatment. This specific means ODBS system may be able to have 11$15 \%$ of equivalent viscous damping ratio by comparing this status to real work. In minimum range of viscous damping, the ODBS gathers $6-10 \%$ of damping ratio in term of hysteresis energy dissipation. On the other hand, according to extended analysis, these equivalent damping quantities are lower in the $\mathrm{x}$-braced and flexural frame. In the other word the ductile capacity of ODBS to absorbing energy is higher than the other systems. 
(a)

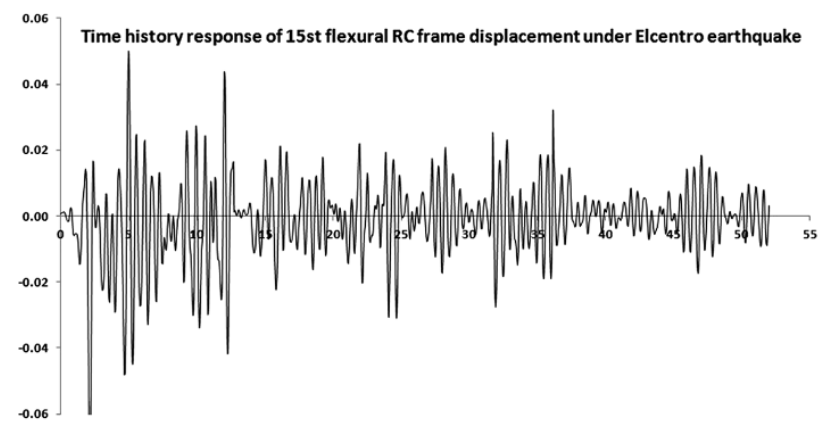

(b)

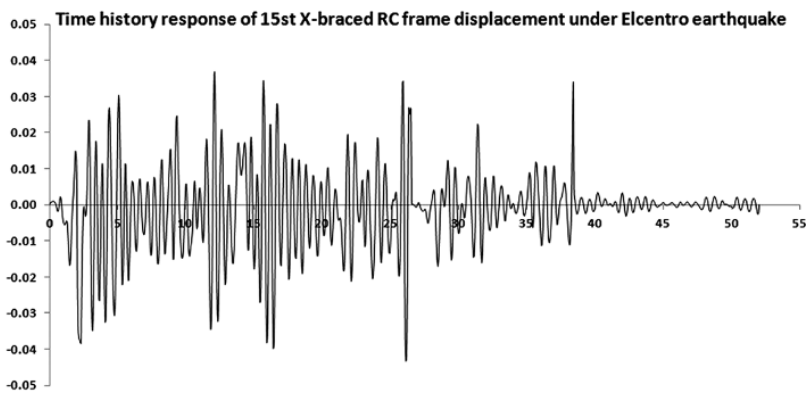

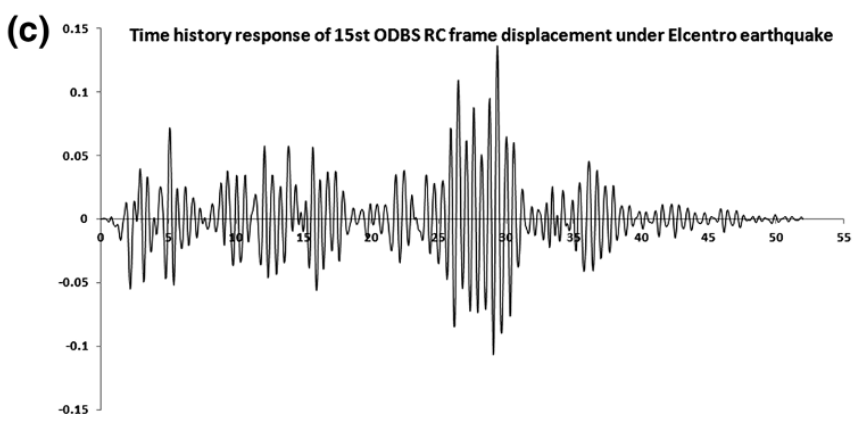

Fig. 31 Displacement response of a Flexural, b ODBS and $\mathbf{c}$ X-braced frame under Elcentro time history analysis.

(a)

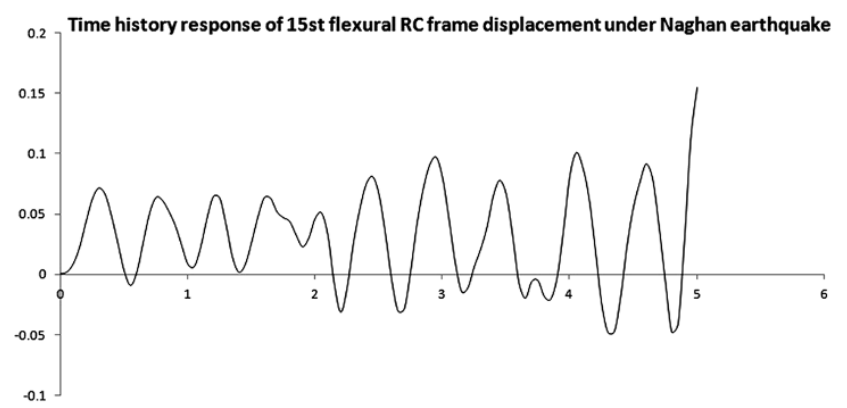

(b)

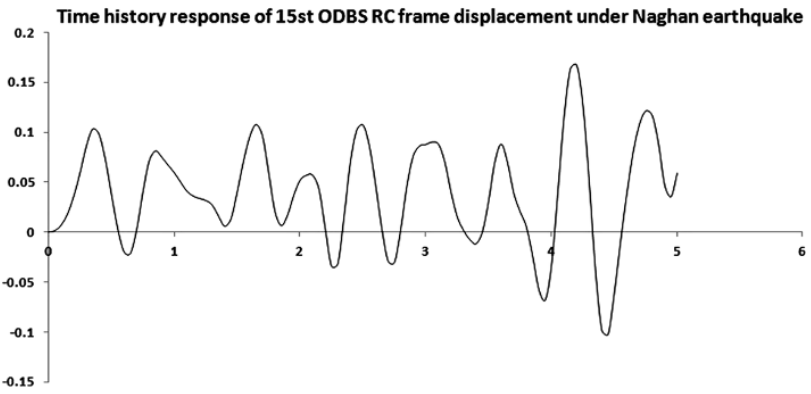

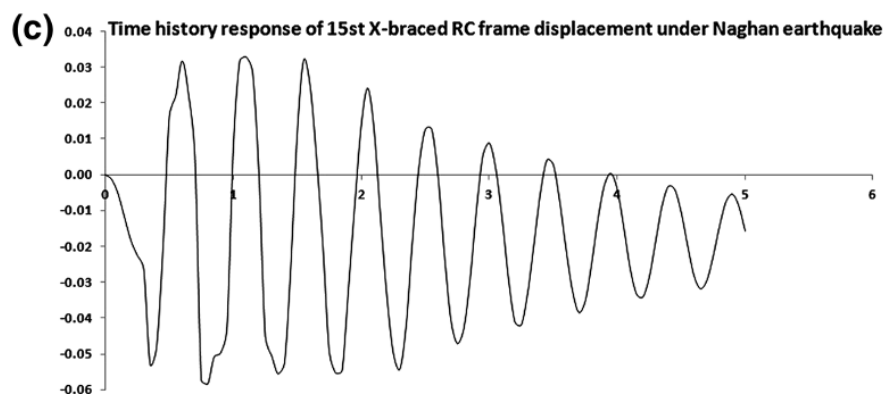

Fig. 32 Displacement response of a Flexural, b ODBS and $\mathbf{c}$ X-braced frame under Naghan time history analysis.

\section{Energy Dissipation for Various Models}

\subsection{Hysteresis Response of Models Under Earthquake Excitations}

Connecting the pick points of hysteresis loops obtained the spectral response that, it is the one of important parameters for control the structural response in the range of period domain. Figure 23 indicates the spectral response acceleration and spectral response displacement in some different case studies. The various models by 2, 6 and 15 stories for three types of flexural, $\mathrm{x}$-brace and off-diagonal bracing system are subjected to Elcentro, Naghan and Tabas accelerogram records.

It means that, after occurring large deformation (displacement or rotation), the flexural frame has been softened and the disability of load bearing in second stage, especially in term of strain hardening, may caused. The results indicate the ODBS system is the cause of adjustment in quantities of the energy stored and the hysteretic energy. This reason may be the cause of the upper equivalent viscous damping ratio for ODBS braced frame in compare with the others. Hysteresis analysis is performed for each system with their 

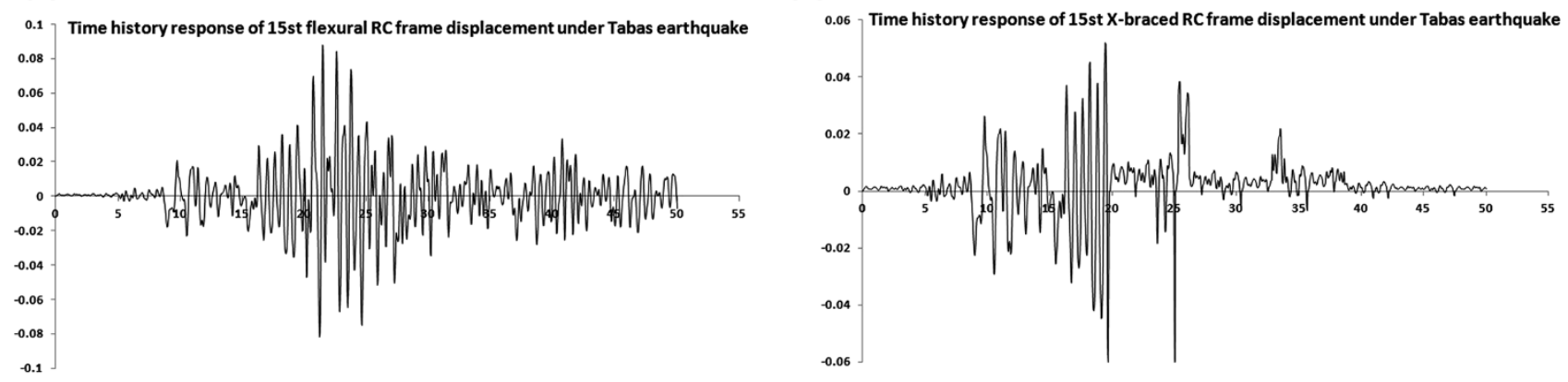

(c)

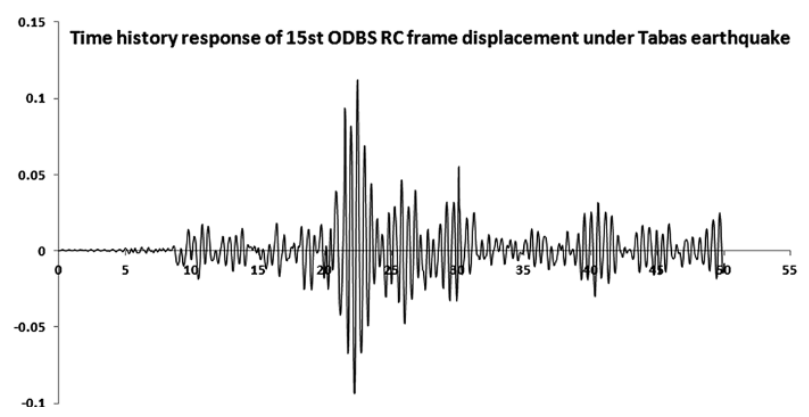

Fig. 33 Displacement response of a Flexural, $\mathbf{b}$ ODBS and $\mathbf{c}$ X-braced frame under Tabas time history analysis.

corresponding stories under earthquake records that are investigated one by one as shown in Figs. 24-29. Also as indicated in figures at center, another ODBS specification is about resisting along the earthquake loads up to last cycles of vibration or even to the moment of collapse, vice versa, sole use of flexural frame is not able to resist earthquake in the next cycles just similar to its initial behaviour.

\subsection{Time History Analysis Response}

Ultimately in last step, the diagrams of time history responses are investigated for different systems of load bearing and under the various seismic records. According to mentioned scaled records, the sightly accelerograms are defined for time history analysis within this research article. As indicated in comparative Fig. 30, the levels of vibration in ODBS system are compared for exciting acceleration and response acceleration.

The level of ODBS response acceleration (in each story by off-diagonal bracing system) is about 41 percent of exciting acceleration. Similar treatment of ODBS has been observed in friction damper device and/or in isolators. Figures 31, 32 and 33 indicate the variation of acceleration and displacement response for various systems and under different earthquakes. For the ODBS system, the number of mode and their vibration's amplitude could be decreased, that this behaviour is suitable for a structure.

For the future, the exact modeling and analysis of ODBS by experimental investigation could be performed and verified by highest level of accuracy. According to obtained results, the influence factor for variation control and energy dissipation of ODBS system is more than other lateral resisting systems, specially compare with flexural and $\mathrm{x}$-braced frame. The ODBS system was very advantages to controlling deteriorations due to loading by short time period just like an isolation damper or viscous damper and/or the composed system of them.

\section{Conclusion}

This research has several results about applying off-diagonal bracing system in reinforced concrete frame. The ODBS is considered in single story and multi stories frame to investigating its behaviour under nonlinear static and dynamic analysis. The results can be explained as below:

(1) FE models are treated properly as verified by experimental investigations. Nonlinear analysis of FE models is indicated as converged response along its ductility confirmations. The finite element analyses are performed by comparative models as Flexural, Xbraced and ODBS braced frames where their results indicate the highest ductility for ODBS. Pushover diagrams are also performed for investigating the capacity of various mentioned frames.

(2) The acceptance criteria for rotations and displacements are compared with related quantities of the ATC manual. The ODBS models had the most rotation at nodal elements, before the collapse level. Each of occurred plastic hinges is deformed elastically and plastically two times and it may be the cause of more energy dissipation.

(3) Also the crack analysis is performed according to finite element models in a time domain consisted of several time steps. The time steps were the steps of imposing displacement. The ODBS system was fully cracked pattern in term of flexural and shear crack. The 
differences between flexural and ODBS systems are indicated in capacity of bearing for both of deformations and loads.

(4) High-rise frames in 2, 6 and 15 floors are modeled numerically for considering ODBS effects on a simple flexural frame. The optimum number of stories to use ODBS system in first story is about 4-12 stories but if the ODBS system utilized for all stories, it has no limitation for number of stories. The only disadvantage of using ODBS in all stories is that it's uneconomically.

(5) Application of ODBS system is considered for different regions and their given results are concentrated along its better behaviour under strong ground motion, because the natural period of ODBS system is high and for preventing the occurrence of resonance phenomenon, it is better that, this system being under strong ground excitation by low excitation's period.

(6) The specific property of ODBS system is about its damping and its ability for dissipating received energy. Along analytical investigation of ODBS system, the equivalent viscous damping ratio is calculated about $11-15 \%$ according to the results. The ODBS is absorbed $6-10 \%$ of damping ratio in term of hysteresis energy dissipation. The ODBS equivalent damping is higher than related quantities for $\mathrm{x}$-braced and flexural frame. The ODBS damping ratio is about 1.8 2.5 times of flexural frame damping.

(7) Mentioned numerical models are also considered to assessing the ODBS hysteretic behaviour. Many hysteresis diagrams are obtained to various models under several earthquake records. Hysteresis curves indicate the ODBS system had less pinching and the most strain energy. The obtained curves are geometrical comparison to calculating its energy dissipated quantities. The absorbed energy for ODBS model was several times of $\mathrm{x}$-bracing system. The strength degradation for flexural frame is more than the other systems. The ODBS system is a sustainable system versus the large number of cycles.

\section{Acknowledgments}

I would like to express my deep gratitude to professors of Shiraz University for their life pattern specially thanks to Profs. H. Seyyedian; S. A. Anvar \& A. R. Ranjbaran. Finally, I wish to specially thanks to Mehri Zoroufian for her support and encouragement throughout my study.

\section{Open Access}

This article is distributed under the terms of the Creative Commons Attribution License which permits any use, distribution, and reproduction in any medium, provided the original author(s) and the source are credited.

\section{References}

Abou Elfath, A., \& Ghobarah, A. (2000). Behaviour of reinforced concrete frames rehabilitated with concentric steel bracing. Canadian Journal of Civil Engineering, 27, 433444.

ACI Committee 318 (2002). Building code requirements for reinforced concrete (ACI 318-02). Detroit, MI: American Concrete Institute.

Altun, F., \& Birdal, F. (2012). Analytical investigation of a three-dimensional FRP-retrofitted reinforced concrete structure's behaviour under earthquake load effect in ANSYS program. Natural Hazards and Earth System Sciences., 12, 3701-3707.

Amiri, G., Gh, R., et al. (2008). Evaluation of performance behaviour of reinforced concrete frame rehabilitated with coaxial steel braces. The Journal of Structure and Steel, 4(4), 17-25.

Amiri, A., \& Tabatabaei, R. (2008). Earthquake risk management strategy plan using nonparametric estimation of hazard rate. American Journal of Applied Sciences, 5(5), 581-585.

Anam, I \& Shoma, Z. N. (2011). Nonlinear properties of reinforced concrete structures, Department of Civil and Environmental Engineering, The University of Asia Pacific, tech_bulletin n \& journal.

ANSYS (2009\&2015). ANSYS manual, ANSYS, INC, Canonsburg, PA 15317, USA.

ATC. (1995a). Structural response modification factors. ATC-19 Report. Applied Technology Council. Redwood City, CA, 1995.

ATC. (1995b). A critical review of current approaches to earthquake-resistant design. ATC-34 Report. Applied Technology Council. Redwood City, CA, 1995.

Badoux, M., \& Jirsa, J. (1990). Steel Bracing of RC Frame for seismic retrofitting. ASCE Journal of Structural Engineering, 116, 55-74.

Bathe, K. J. (1996). Finite element procedures. Upper Saddle River, NJ: Prentice Hall.

Bazant, Z. P., \& Becq-Giraudon, E. (2002). Statistical prediction of fracture parameters of concrete and implications for choice of testing standard. Cement and Concrete Research, 32, 529-556.

Berberian, M., \& Navai I. (1977). Naghan (chahar mahal bakhtiari-high zagros, Iran) earthquake of 6 April 1977: A preliminary field report and a seismotectonic discussion. Geological Survey Iran, 40, pp. 51-77.

Bozorgnia, Y., \& Bertero, V. (2004). Earthquake engineering: From engineering seismology to performance-based engineering. Boca Raton, FL: CRC Press.

Bush, T. D., Wyllie, L. A., \& Jirsa, J. O. (1991). Observations on two seismic strengthening schemes for concrete frames. Earthquake Spectra, 7(4), 511-527.

Constantinou, M. C., Soong, T. T., \& Dargush, G. F. (1998). Passive energy dissipation systems for structural design and retrofit. Monograph no. 1. Buffalo, NY: Multidisciplinary Center for Earthquake Engineering Research. 
Cotsovos, D. M. (2013). Cracking of RC beam/column joints: Implications for the analysis of frame-type structures. Engineering Structures, 52, 131-139.

El-Metwally, S., \& Chen, W. F. (1988). Moment-rotation modelling of reinforced concrete beam-column connections. ACI Structural Journal, 85(4), 384-394.

FEMA-356, \& FEMA-270. (2000). Pre-standard and commentary for seismic rehabilitation of buildings. Washington, DC: Federal Emergency Federal Agency.

Ghaffarzadeh, H., \& Maheri, M. R. (2006). Cyclic tests on the internally braced RC frames. Journal of Seismology and Earthquake Engineering (JSEE), 8(2), 177-186.

Ghobarah, A., \& Abou Elfath, A. (2001). Rehabilitation of a reinforced concrete frame using eccentric steel bracing. Engineering Structures, 23, 745-755.

Gourabi, A., \& Yamani, M. (2011). Active faulting and quaternary landforms deformation related to the nain fault. American Journal of Environmental Sciences, 7(5), 441447.

Guan, Y., Cheng, X., \& Zhang, Y. (2011). Study on the earthquake disaster reduction information management system and its application. International Journal of Intelligent Systems and Applications, 1, 51-57.

Kawamata, S., \& Ohnuma, M. (1981). Strengthening effect of eccentric steel braces to existing reinforced concrete frames, In 7WCEE Conference, Proceedings of 2nd Seminar on Repair and Retrofit of Structures. Ann Arbor, MI: NSF.

Kent, D. C., \& Park, R. (1971). Flexural members with confined concrete. Journal of the Structural Division ASCE, 97, 1969-1990.

Maheri, M. R., \& Akbari, R. (2003). Seismic Behaviour factor, $\mathrm{R}$, for steel x-braced and knee-braced RC building. Engineering Structures, 25, 1505-1513.

Maheri, M. R., \& Ghaffarzadeh, H. (2008). Connection overstrength in steel-braced RC frames. Engineering Structures, 30(7), 1938-1948.

Maheri, M. R., \& Hadjipour, A. (2003). Experimental investigation and design of steel brace connection to $\mathrm{RC}$ frame. Engineering Structures, 25(13), 1707-1714.

Maheri, M. R., Kousari, R., \& Razzazan, M. (2003). Pushover tests on steel X-braced and knee-braced RC frames. Engineering Structures, 25(13), 1697-1705.

Maheri, M. R., \& Sahebi, A. (1995a). Experimental investigation of the use steel bracing in reinforced concrete frames. In Proceedings of 2nd International Conf. on Seismology and Earthquake Eng., Tehran, Islamic Republic of Iran, Vol. 1, pp.755-784.

Maheri, M. R., \& Sahebi, A. (1995b). Use of Steel bracing in reinforced concrete frames. Engineering Structures, 9, 545 552.

Masri, M., \& Goel, S. C. (1996). Seismic design and testing of an RC slab-column frame strengthening by steel bracing. Earthquake Spectra, 12(4), 645-666.

Mastrandrea, L., \& Piluso, V. (2009a). Plastic design of eccentrically braced frames, I: Moment-shear interaction. Journal of Constructional Steel Research, 65(5), 10071014.
Mastrandrea, L., \& Piluso, V. (2009b). Plastic design of eccentrically braced frames, II: Failure mode control. Journal of Constructional Steel Research, 65(5), 1015-1028.

Moghaddam, H. A., \& Estekanchi, H. (1994). On the characteristics of an off-diagonal bracing system. Elsevier, Journal of Constructional Steel Research, 35, 361-376.

Moghaddam, H. A., \& Estekanchi, H. (1999). Seismic behaviour of off-diagonal bracing systems. Elsevier, Journal of Constructional Steel Research, 51, 177-196.

Mohyeddin, A., Helen, M., Goldsworthy, B., \& Emad, F. Gad. (2013). FE modelling of RC frames with masonry infill panels under in-plane and out-of-plane loading. Engineering Structures, 51, 73-87.

PEER. (2005). Strong motion database http://peer.berkeley.edu Retrieved 4 Apr 2009.

Providakis, C. P. (2008). Pushover analysis of base-isolated steel-concrete composite structures under near-fault excitations. Soil Dynamics and Earthquake Engineering, 28(4), 293-304.

Ramin, K. (2009). Seismic investigation and numerical analysis of RC frame retrofitted by off diagonal steel bracing system (ODBS) Master science of Shiraz university (Thesis in Farsi).

Rastiveis, H., Samadzadegan, F., \& Reinartz, P. (2013). A fuzzy decision making system for building damage map creation using high resolution satellite imagery. Natural Hazards and Earth System Sciences, 13, 455-472.

Ravi Kumar, G., Kalyanaraman, V., \& Kumar, S. (2007). Behaviour of frames with non-buckling bracing under earthquakes. Journal of Constructional Steel Research, Elsevier, 63, 254-262.

Razavian Amrei, S. A., Ghodrati Amiri, G., \& Rezaei, D. (2011). Evaluation of horizontal seismic hazard of Naghan, Iran World Academy of Science, Engineering and Technology, Vol. 5.

Roeder, C., Popov, E. (1977). Inelastic behaviour of eccentrically braced steel frames under cyclic loading, Univ. of Calif. Berkeley, CA.

SAP2000 (ver11.0). (2010). Software and manual. Berkeley, CA: CSI: Computers and Structures Inc.

Scott, B. D., Park, R., \& Priestley, M. J. N. (1982). Stress-strain behaviour of concrete confined by overlapping hoops at low and high strain rates. ACI Journal, 79, 13-27.

Steidl, J. H., \& Lee, Y. (2000). The SCEC phase III strongmotion database. Bulletin of the Seismological Society of America, 90, S113-S135.

Sugano, S., \& Fujimura, M. (1980). Seismic strengthening of existing reinforced concrete building. In Proceeding of the 7th World Conference on Earthquake Eng., Turkey, Part 1, Vol. 4, pp. 449-459.

Tasnimi, A., \& Masoumi, A. (1999). Study of the behaviour of reinforced concrete frames strengthened with steel brace. In Third international conference on seismology and seismic engineering. Tehran, Iran.

Taucer, F., Spacone, E., \& Filippou, F. C. (1991). A fiber beamcolumn element for seismic response analysis of reinforced concrete structures. Berkeley, CA: Earthquake Engineering Research Center, University of California at Berkeley. 
Uang, C. M. (1991). Establishing R (or Rw) and Cd factors for building seismic provisions. Journal of structural Engineering, ASCE, 117, 19-28.

Vatani Oskouei, A., \& Rafi'ee, M. H. (2009). Damage modeling in reinforced concrete bending frames originated by quake and its restoration using X-bracing system. Esteghlal, 28(1), 49-73.

Willam K.J., \& Warnke E.P. (1974). Constitutive model for the triaxial behaviour of concrete. In Proceedings of the international association for bridge and structural engineering, Vol. 19, (pp. 1-30). Bergamo, Italy.

Yaghmaei Sabegh, S. (2011). Stochastic finite fault modeling for the 16 september 1978 Tabas, Iran, earthquake. IJE Transaction A Basics, 24(1), 15-24.

Youssefa, M. A., Ghaffarzadehb, H., \& Nehdia, M. (2007). Seismic performance of RC frames with concentric internal steel bracing. Engineering Structures, 29, 1561-1568. 